\title{
Activation of cell surface GRP78 decreases endoplasmic reticulum stress and neuronal death
}

\author{
Morgane Louessard ${ }^{1}$, Isabelle Bardou ${ }^{1}$, Elö̈se Lemarchand ${ }^{1}$, Audrey M Thiebaut ${ }^{1}$, Jérôme Parcq ${ }^{1}$, Jérôme Leprince ${ }^{2}$, Anne Terrisse ${ }^{3}$, \\ Valérie Carraro ${ }^{3}$, Pierre Fafournoux ${ }^{3}$, Alain Bruhat ${ }^{3}$, Cyrille Orset ${ }^{1}$, Denis Vivien ${ }^{1,4}$, Carine Ali ${ }^{1}$ and Benoit D Roussel ${ }^{*, 1}$
}

The unfolded protein response (UPR) is an endoplasmic reticulum (ER) -related stress conserved pathway that aims to protect cells from being overwhelmed. However, when prolonged, UPR activation converts to a death signal, which relies on its PERKelF2 $\alpha$ branch. Overactivation of the UPR has been implicated in many neurological diseases, including cerebral ischaemia. Here, by using an in vivo thromboembolic model of stroke on transgenic ER stress-reporter mice and neuronal in vitro models of ischaemia, we demonstrate that ischaemic stress leads to the deleterious activation of the PERK branch of the UPR. Moreover, we show that the serine protease tissue-type plasminogen activator (tPA) can bind to cell surface Grp78 (78 kD glucose-regulated protein), leading to a decrease of the PERK pathway activation, thus a decrease of the deleterious factor CHOP, and finally promotes neuroprotection. Altogether, this work highlights a new role and a therapeutic potential of the chaperone protein Grp78 as a membrane receptor of tPA capable to prevent from ER stress overactivation.

Cell Death and Differentiation (2017) 24, 1518-1529; doi:10.1038/cdd.2017.35; published online 23 June 2017

The endoplasmic reticulum (ER) stress is a conserved cellular process that activates the unfolded protein response (UPR) that controls the correct functioning of the ER. ${ }^{1}$ The UPR combines two responses: an early inhibition of protein synthesis, to avoid protein overload within the ER; and a later upregulation of genes that help protein folding, to clear the ER from native/aberrant proteins. ${ }^{2}$ If prolonged, the UPR triggers death signals. ${ }^{3}$

Three sensors present at the ER membrane ensure a correct detection of ER stress: IRE1 (inositol-requiring protein1); ATF6 (activating transcription factor 6); and PERK (protein kinase RNA (PKR)-like ER kinase). IRE1 and ATF6 are normally bound to, and thus inactivated by the ER chaperone Grp78 (78 kDa glucose-related protein, also called Bip for binding immunoglobulin protein). Under stress conditions, Grp78 disengages from IRE1 and ATF6, leading to their activation and the subsequent expression of UPR genes (chaperones, folding and ER proteins). ${ }^{4}$ Like the other two sensors, PERK is held inactive by the binding of Grp78. Under stress conditions, PERK phosphorylates its unique substrate, elF2 $a$ (eukaryotic translation initiation factor-2 $a$-subunit), ${ }^{5}$ resulting in a global protein synthesis shutdown. ${ }^{6}$ Paradoxically, PERK-mediated elF2a phosphorylation also activates the transcription of specific genes, including ATF4 (activating transcription factor 4), which triggers a transcriptional programme of stress-responsive genes ${ }^{7}$ and of the transcription factor CHOP (C/EBP homologous protein); in case of ER stress overactivation, $\mathrm{CHOP}$ will induce death signals. ${ }^{8}$ Another target of ATF4 and CHOP, GADD34 (growth arrest and DNA damage-inducible protein 34 , a protein phosphatase
1 regulatory subunit), serves as a negative feedback loop by dephosphorylating elF2a, allowing the recovery of protein translation ${ }^{4}$ (Figure 1a).

These molecular events have been implicated in many neurological diseases, including Alzheimer's disease, Parkinson's disease, Huntington's disease and stroke. ${ }^{4,9}$ Many stroke models are known to activate the UPR. ${ }^{10,11}$ This activation is likely due to the energetic failure and the attendant dysfunctions of calcium pumps, ER-calcium depletion, chaperone dysfunction and the eventual accumulation of misfolded proteins. ${ }^{4,12}$ For example, activation of the PERK branch is evidenced by elF2a phosphorylation in a model of hypoxia/ischaemia in mice. ${ }^{13}$ Moreover, CHOP and GADD34 - the downstream targets of phosphorylated elF2 $a$ (phospho-elF2a) - are also increased during cerebral ischaemia. $^{14-17}$

In our study, we investigated ER stress-induced neuronal death by using an in vivo model of stroke and two different models of ischaemia/reoxygenation (ex vivo and in vitro). We demonstrate that the PERK branch of the UPR can be controlled by the activation of translocated-ER-resident chaperone Grp78 to the neuronal surface by tissue-type plasminogen activator (tPA). Binding of tPA to Grp78 results in a decrease of PERK/elF2 $a$ activation, and thus a decrease of the deleterious factor $C H O P$, leading to neuroprotection. For the first time, we describe an active role of cell surface Grp78 signalling in the control of ER stress, thus opening new therapeutic strategies for neurological diseases, especially during stroke.

${ }^{1}$ Normandie Univ, UNICAEN, INSERM, Physiopathology and Imaging of Neurological Disorders, Caen, France; ${ }^{2}$ Normandie Univ, UNIROUEN, INSERM, Laboratoire Différenciation et Communication Neuronale et Neuroendocrine, Plate-forme de Recherche en Imagerie Cellulaire de Normandie (PRIMACEN), Rouen, France; ${ }^{3}$ INRA, UMR 1019 Nutrition Humaine, Centre de Clermont-Ferrand-Theix, Saint Genès Champanelle, France and ${ }^{4}$ Clinical Research Department, Medical Center, University Caen Normandy, Centre Hospitalo-Universitaire Caen Côte de Nacre, Caen, France

${ }^{*}$ Corresponding author: BD Roussel, GIP Cyceron-Caen Basse-Normandie University, INSERM U919, GIP Cyceron, Boulevard Becquerel, BP5229, Caen 14074, France. Tel: +33 2 31470213; Fax: +33 2 31470222; E-mail: broussel@ cyceron.fr

Received 26.12.16; revised 20.2.17; accepted 23.2.17; Edited by N Bazan; published online 23.6.17 
a

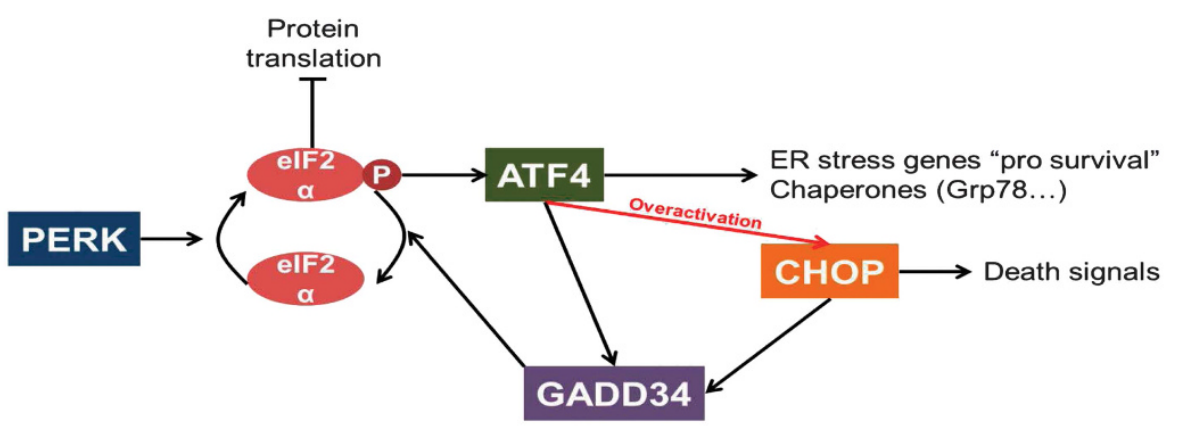

b
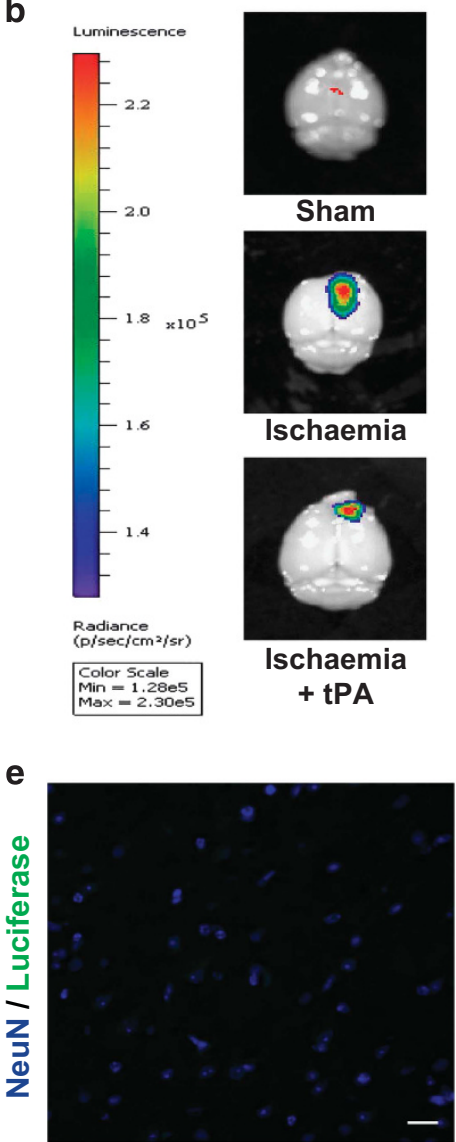

Sham

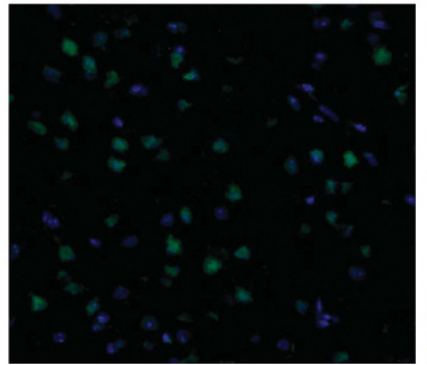

Ischaemia

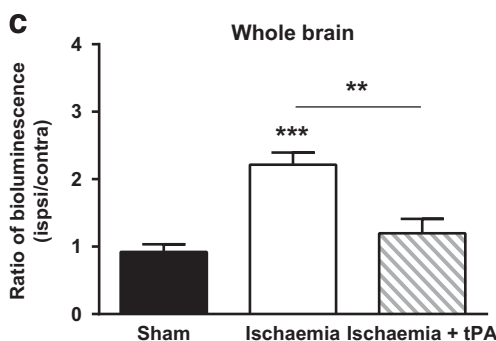

d Brain extracts

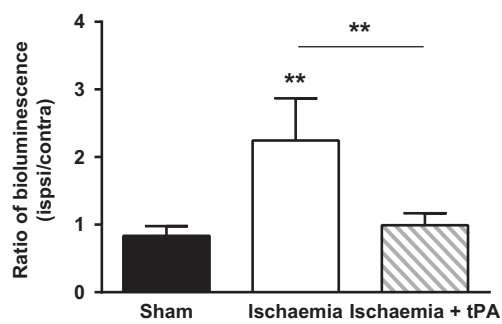

Figure 1 tPA protects neurones from ischaemia-induced ER stress in a thromboembolic model of stroke. (a) Diagram of the PERK branch of the UPR: PERK is an ER membrane-bound sensor activated under stress conditions. Once activated, it phosphorylates elF2 $\alpha$ leading to a global shutdown in protein translation. Paradoxically, phosphoelF2 $\alpha$ promotes ATF4 expression and subsequent protein-folding genes to restore ER homeostasis, including GADD34 to restore protein synthesis by dephosphorylating elF2 $\alpha$. If ER stress is over-activated, ATF4 leads to the expression of CHOP, partially responsible of ER stress-mediated death. (b) Representative cerebral luminescence intensities following sham surgery, thromboembolic ischaemia alone or coupled to thrombolysis with tPA (10 mg/kg IV) ( $n=9$ for sham animals and $n=10$ for ischaemia and ischaemia ttPA). (c) Mean ipsilateral/contralateral hemispheres ex vivo bioluminescence ( $n=9$ for sham animals and $n=10$ for ischaemia and ischaemia+tPA). (d) Mean ipsilateral/ contralateral cortical lysates bioluminescence (data are represented as mean \pm S.E.M.; $n=9$ for sham animals and $n=10$ for ischaemia and ischaemia+tPA). (e) Representative immunostainings against luciferase (green) and NeuN (blue) in the peri-infarct area. $\left({ }^{\star} P<0.05,{ }^{\star \star} P<0.01,{ }^{\star \star \star} P<0.001\right.$; Mann-Whitney test; scale bar, $20 \mu \mathrm{m}$ )

\section{Results}

Thromboembolic ischaemia induces activation of PERK/ATF4 branch of ER stress and is decreased by thrombolysis. CARE-Luciferase mice allow an in vivo detection of the activation of the PERK-elF2 $a$ branch of the $\mathrm{UPR}^{18}$ (Figure 1a). CARE-Luciferase mice were subjected to thromboembolic stroke, induced by the injection of thrombin within the middle cerebral artery. ${ }^{19}$ This model allows thrombolysis by recombinant IPA in the same conditions than its use in clinic: a group of mice were thrombolysed with IPA $20 \mathrm{~min}$ after stroke induction $(10 \mathrm{mg} / \mathrm{kg}$ iv; bolus and then infusion over $40 \mathrm{~min}$ ) while sham group received saline. After $24 \mathrm{~h}$, mice were perfused and brain were harvested to 
measure ex vivo luciferase activity in the ischaemic (ipsilateral) and contralateral hemispheres. As shown on the images and on the quantifications (Figure $1 b$ and $c$ ), ischaemic stroke increased by 2.4-fold the bioluminescent signal compared to sham conditions (ipsi/contralateral hemispheres) ( $n=9$, $P<0.001)$. Thrombolysis with tPA reduced by $46 \%$ ischaemia-induced luciferase signal $(n=9 ; P<0.01)$. Concordant with the ex vivo findings, in vitro luciferase assays (Figure 1d) showed a strong ischaemia-induced luciferase activity (+270\% versus sham mice; $n=9 ; P<0.01)$ that was reduced by tPA-induced thrombolysis (56\% reduction compared to ischaemia alone; $n=9, P<0.01)$. Immunostainings against luciferase also highlighted in the peri-infarct cortical region a strong ischaemia-induced labelling which was reduced by thrombolysis (Figure 1e). However, because tPA can positively or negatively control neuronal survival through multiple pathways $\mathrm{s}^{20,21}$ in addition to its thrombolytic effects, we wondered if the decrease of ER stress observed after thrombolysis was only due to its vascular properties or not.

\section{OGD/reoxygenation induces a deleterious activation of} the PERK branch of ER stress that is counteracted by tPA. IPA is now considered as a neuromodulator. ${ }^{20,22}$ Because it is complicated to decipher its parenchymal roles from its thrombolytic action, we decided to use a model of ischaemia where thrombolysis is not necessary: an ex vivo model of hippocampal slices subjected to $40 \mathrm{~min}$ of OGD followed by reoxygenation ( $O G D_{\text {reox }}$ ) (Figure 2a). To ensure ER stress activation, we measured the level of elF2a phosphorylation by western blots $24 \mathrm{~h}$ after the experiment.

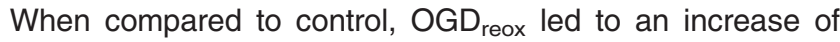
elF2 $a$ phosphorylation (Figure $2 \mathrm{~b}$ and quantification in Figure 2c, 2.5-fold increase, $P<0.01$ ), confirming the activation of ER stress. Interestingly, tPA prevented OGD reoxmediated elF2 $a$ phosphorylation (Figure $2 \mathrm{~d}$ and quantification in Figure 2c, $n=6, P<0.05$ ) independently from its thrombolytic properties. We also assessed cell death, by propidium iodide staining (Figure $2 \mathrm{~d}$ ) and as observed in vivo after ischaemic stroke, tPA protected from $O_{\text {GD }}$ reox-induced cell death (Figure $2 \mathrm{e}, 60 \%$ of protection, $n=5, P<0.01$ ).

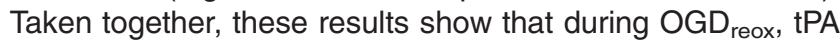
reduces the activation of the PERK-elF2 $a$ branch of the UPR independently of its thrombolytic activity.

OGD/reoxygentation overactivates the PERK branch of ER stress in pure cortical neurones and is decreased by tPA. To study the mechanism of action of tPA, we next used cultures of pure cortical neurones subjected to $O G D_{\text {reox }}$ (Figure 3a). In these conditions, the PERK-elF2 $a$ branch was activated, as illustrated by immunostainings against phospho-elF2a (Figure 3b). ER stress activation increased as a function of the duration of OGD, as shown by the extent of elF2 $a$ phosphorylation ratio compared to the total form, after various time of OGD and followed by $4 \mathrm{~h}$ of reoxygenation (Figure 3c and densitometries in Figure 3d, 1.84-, 2.68and 3.86-fold increase of elF2 $a$ phosphorylation at 10, 40 and $60 \mathrm{~min}$ of OGD, respectively, $P<0.05)$. In this neuronal model, tPA $300 \mathrm{nM}$ also prevented the activation of the PERK branch as illustrated by immunostainings (Figure $3 b$ ) and immunoblots against phospho-elF2a (Figure $3 c$ and densitometries in Figure 3d, tPA reduces by $44 \%, 46 \%$ and $40 \%$ the phosphorylation of elF2 $a$ after 10,40 and 60 min of OGD reox, respectively, $P<0.05)$. We also studied by qPCR the transcriptional downstream targets of phospho-elF2a (Figure 1a). OGD reox increased mRNA levels of ATF4, CHOP, GADD34 and Grp78 (Figure 3e) by 2-, 1.6-, 1.54- and 1.6fold, respectively. This ER stress activation measured by qPCR was totally prevented in the presence of tPA, except for Grp78 (Figure 3e). In parallel to these evidence of timedependent activation of the PERK-elF2 $a$ branch, we also found that $O G D_{\text {reox }}$ induced a neuronal death of which the extent increased with the duration of OGD (Supplementary Figure 1; Spearman correlation test: $\rho=0.777$; $P<0.0001$ ) and that was correlated to the levels of phospho-elF2 $a$ (Spearman correlation test: $\rho=0.671 ; \quad P=0.026$ ). Co-treatment with tPA $(300 \mathrm{nM})$ reduced by $38 \%$ the extent of neuronal loss induced by $\mathrm{OGD}_{\text {reox }}(40 \mathrm{~min}$ OGD followed by $4 \mathrm{~h}$ reoxygenation; Figure $3 f, P<0.01$ ), showing a neuroprotective action of tPA via an alleviation of the recruitment of the PERK branch of the UPR in ischaemic neurones.

The neuronal ER continuity is preserved under OGD/ reoxygenation in the presence of tPA. ER dysfunction is often associated to ER swelling and fragmentation. To visualize the neuronal ER continuity/integrity in our experimental conditions, we performed live imaging of neurones with the cell-permeant dye ER tracker (Figure 4). Due to the use of glass bottom Petri dishes for the confocal acquisition, neurones need the presence of astrocytes to attach to the glass bottom part; we then adapted the protocol of $O G D_{\text {reox }}$ to $1 \mathrm{~h}$ of OGD, in order to obtain the same level of cell death than 40 min OGD on pure cortical neurones. Z-stack acquisitions were performed to enable a $3 \mathrm{D}$ reconstruction by Imaris Software (Bitplane; Concord, MA, USA) (representative reconstruction Figure $4 \mathrm{a}$, blue images). In control conditions (with or without $300 \mathrm{~nm}$ tPA), the ER continuity was preserved with an ER surrounding the nucleus and projecting in neurites (Figure 4a). However, after OGD reox the ER continuity was lost, with an apparent swelling and an ER fragmentation (Figure $4 \mathrm{a}$, blue images). When tPA was added during the OGD reox, ER continuity was preserved. Neuronal swelling was estimated by measuring the somatic diameter of neurones (10 per condition, in five distinct microscopic fields; each individual neurones was recorded every hour) after staining with the ER tracker as illustrated on the images at $4 \mathrm{~h}$ (Figure $4 \mathrm{a}$, green images). Under control conditions, tPA $300 \mathrm{nM}$ alone did not modify the neuronal body diameter, while $\mathrm{OGD}_{\text {reox }}$ led to a 1.5-, 1.8-, 2.11-, 2.26- and 2.34-fold increase of neuronal body diameter at t0, t1, t2, t3 and t4 respectively, ${ }^{* *} P<0.001$ compared to control). When tPA is added during OGDreox, the neuronal body diameter increased over time (Figure 4b, 1.05-, 1.1-, 1.16- and 1.18-fold at to, t1, t2, t3 and t4 respectively; ${ }^{\star \star} P<0.01$, ${ }^{* * *} P<0.001$ compared to control) but less than under OGD reox alone (Figure 4b, 31\%, 29\%, 22\%, 23\% less than $\mathrm{OGD}_{\text {reox }}$ at to, t1, t2, t3 and t4, respectively; $P<0.001$ compared to $\mathrm{OGD}_{\text {reox }}$ alone). It demonstrates that tPA is able to maintain ER continuity and the neuronal morphology under OGD reox. 
a

\section{$O G D$}

\section{reoxygenation}

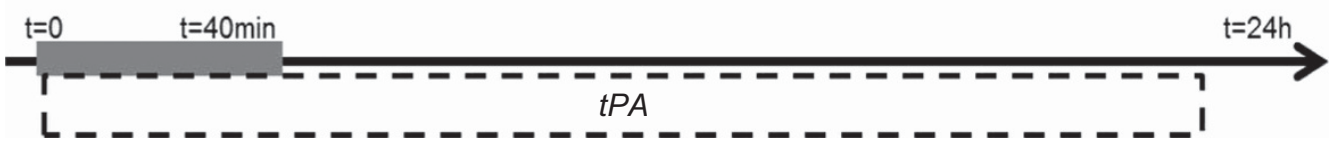

b

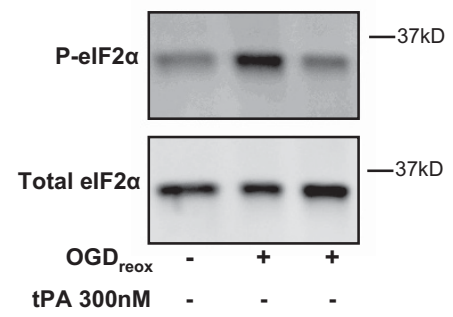

d

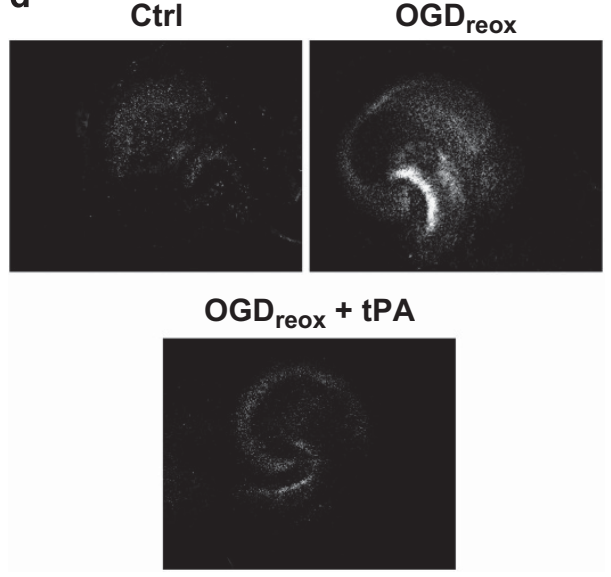

C

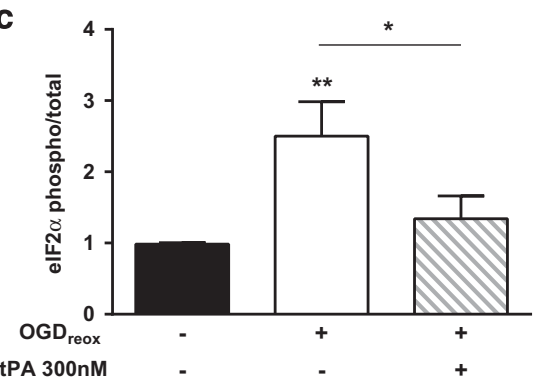

e

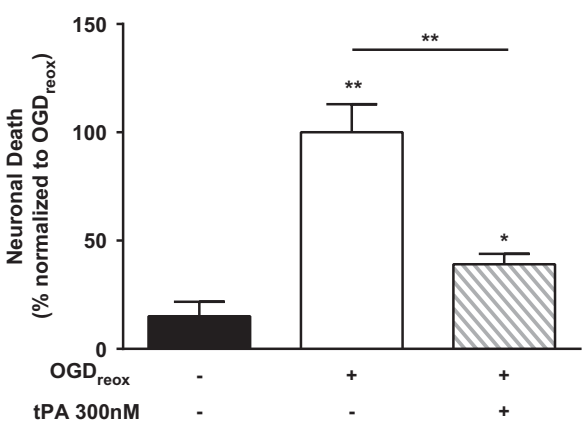

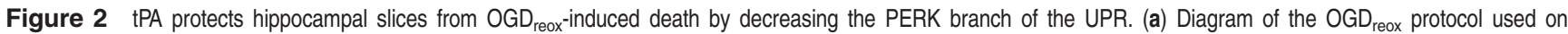
hippocampal slices. Slices were washed with OGD media and stayed under OGD conditions during $40 \mathrm{~min}$, followed by a $24 \mathrm{~h}$ reoxygenation period. (b) Representative western blots against phosphor - and total elF2 $\alpha$ in hippocampal slices subjected or not to $O G D_{\text {reox }} \pm 300 \mathrm{nM}$ tPA. (c) Corresponding ratio of the phosphorylated versus total form of elF2 $\alpha$ (data are represented as mean \pm S.E.M. $n=6,{ }^{\star} P<0.05$; ${ }^{* \star} P<0.01$; Mann-Whitney test). (d) Representative propidium iodide stainings of slices $24 \mathrm{~h}$ after $40 \mathrm{~min}$ of OGD (except Ctrl) in presence or not of $300 \mathrm{nM} \mathrm{TPA}($ Scale bar, $10 \mu \mathrm{M})$. (e) Mean of propidium iodide-positive cells in slices $24 \mathrm{~h}$ after treatments and normalized to the OGD condition (data are represented as mean \pm S.E.M. $n=5$ independent experiments; ${ }^{*} P<0.05$; ${ }^{\star *} P<0.01$; Mann-Whitney test)

tPA decreases the PERK-elF2 $a$ branch of the UPR by a mechanism dependent on its lysine-binding site. We then investigated the mechanisms by which tPA decreases the PERK branch of ER stress and death under OGD reox. We first used a proteolytically inactive form of tPA (itPA: tPAdGGACK; $300 \mathrm{nM}$ ) and showed that despite its lack of enzymatic activity, itPA remained able to confer neuroprotection (Figure 5a, 19\% of neuronal death for itPA under OGD reox; $50 \%$ for $\mathrm{OGD}_{\text {reox }}$ alone; and $31 \%$ for $\mathrm{tPA}$ and $\mathrm{OGD}_{\text {reox }}$, $P<0.001)$. The growth factor domain of tPA confers antiapoptotic capacity through its binding to the EGF receptor. $^{23,24}$ However, AG1478 $(5 \mu \mathrm{M})$, an EGFR tyrosine kinase inhibitor, did not prevent the beneficial effect of tPA during $\mathrm{OGD}_{\text {reox }}$ (Figure 5b, 31\% of neuronal death for tPA under $O G D_{\text {reox }} ; 26 \%$ for $\mathrm{tPA}+\mathrm{AG} 1478$ under $\mathrm{OGD}_{\text {reox }}$ ), excluding a role for EGF receptor. tPA can also interact through its finger domain with LRP-1 (type 1 low-density lipoprotein receptor-related protein) to promote $\mathrm{NF}_{\mathrm{KB}}$ activation $^{25}$ and Akt phosphorylation. ${ }^{26}$ The addition of RAP (receptor-associated protein) (500 nM), a competitive LRP-1 antagonist, did not reverse the protective effect of tPA (Figure $5 \mathrm{c}, 31 \%$ of neuronal death for tPA under OGD reox; $38 \%$ for tPA+RAP under $\left.O G D_{\text {reox }}\right)$. The lysine-binding site (LBS) contained in the Kringle 2 domain of IPA is involved in the interaction of tPA with several partners (for review ref. 22). In order to compete with the binding of its LBS, we used the lysine analogue TXA (tranexamic acid) at the same concentration than IPA $(300 \mathrm{nM})$. Interestingly, TXA reversed the protective effect of tPA during $O$ GD $_{\text {reox }}$ (Figure $5 d, 27 \%$ of neuronal death for tPA under $\mathrm{OGD}_{\text {reox }} ; 41 \%$ for tPA+TXA under $\left.O G D_{\text {reox }}, P<0.05\right)$, suggesting a role for the LBS contained within the Kringle 2 domain of tPA to mediate its action on neuroprotection during $\mathrm{OGD}_{\text {reox }}$.

OGD/reoxygenation promotes cell surface Grp78, and its activation induces a beneficial decrease of ER stress. It is now well accepted that under ER stress conditions, the ER-resident chaperone Grp78 translocates to the cell 
surface. $^{27,28}$ To confirm this in our OGD reox conditions, we biotinylated membrane proteins before and after $40 \mathrm{~min}$ of OGD, and we performed an avidin pull-down followed by a western blotting against Grp78. We show an increase of cell surface Grp78 after OGD compared to control (Figure 6a), in favour of a translocation of Grp78 to the neuronal membrane.
We then checked the ability of tPA to be a cell surface Grp78 ligand. Immunoprecipitations (IP) were performed with both Grp78 and tPA antibodies on neurones subjected to OGD reox and treated or not with $300 \mathrm{nM}$ of tPA (Figure 6b). The pulldown with Grp78 antibodies revealed a Grp78 band by western blot as a positive control, and the tPA pull-down also

a

$O G D$

\section{reoxygenation}

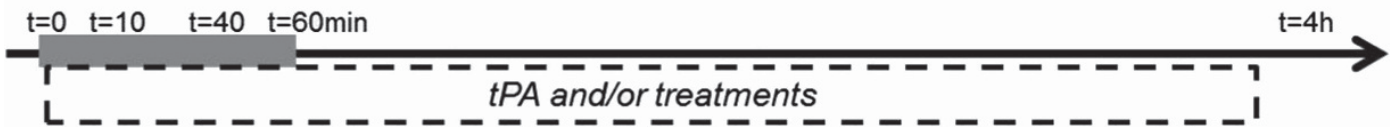

b

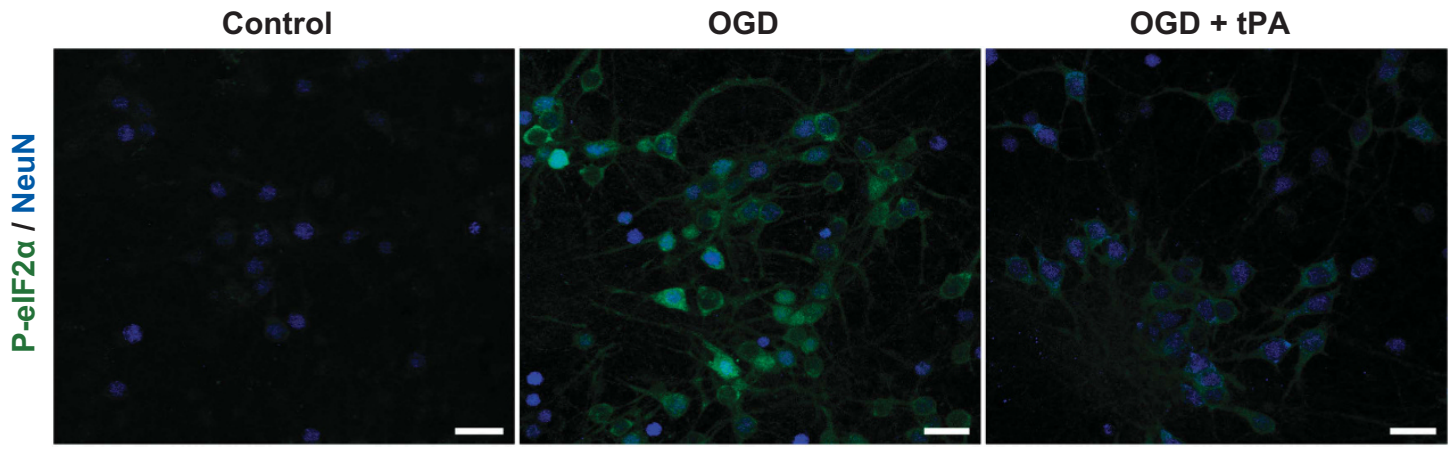

C

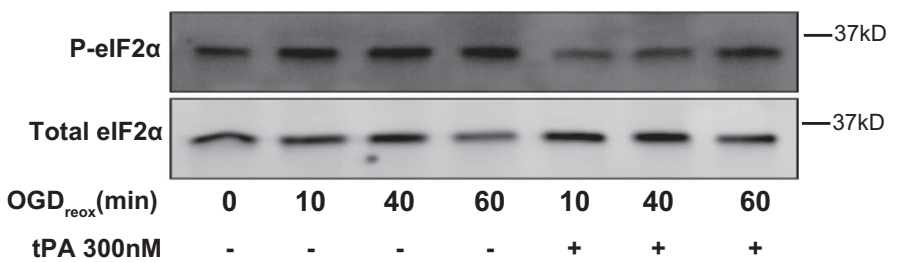

e
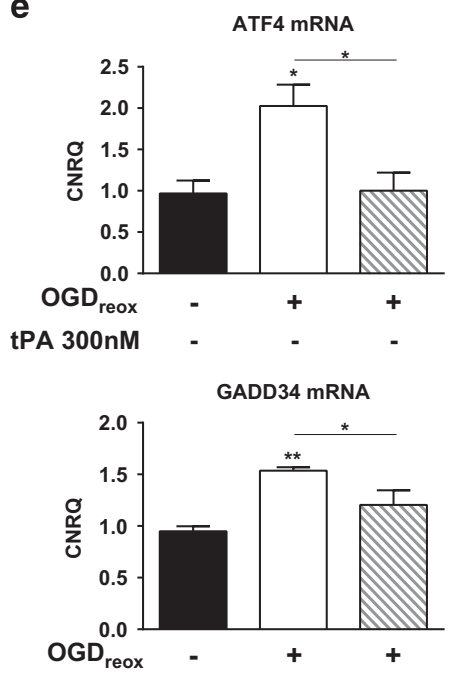

tPA 300nM
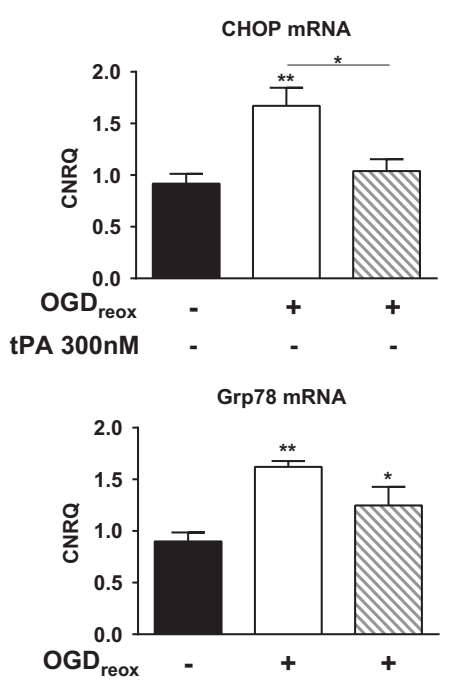

d

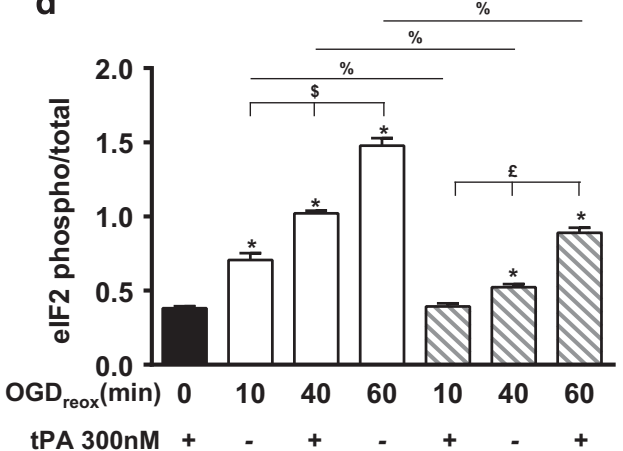

f

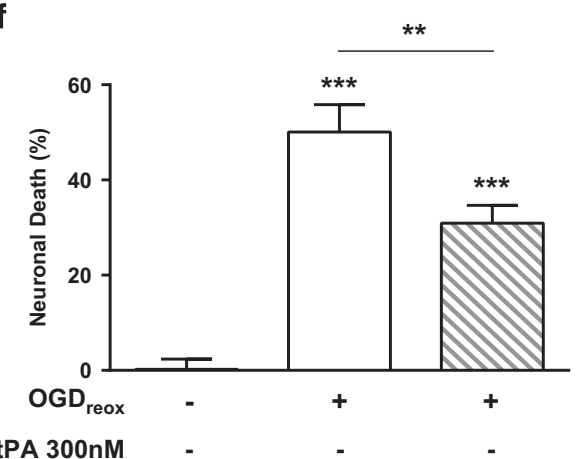


a
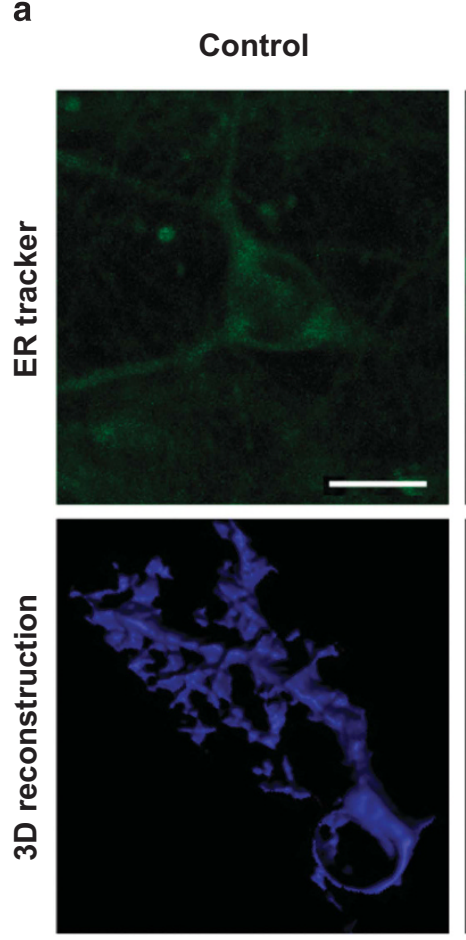

Control + tPA
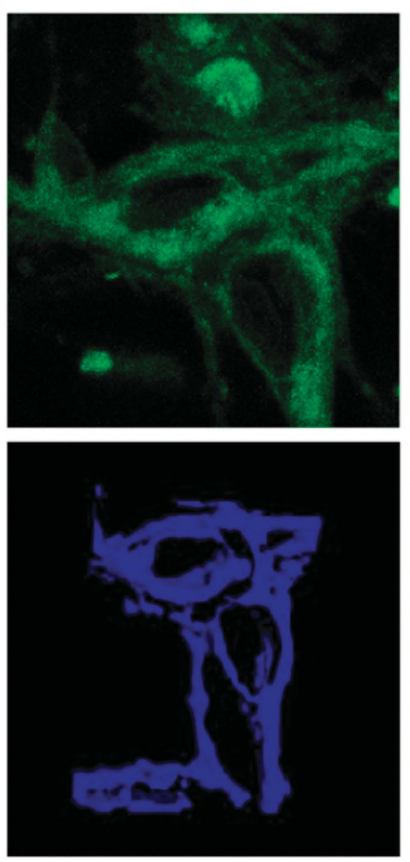

OGD reox
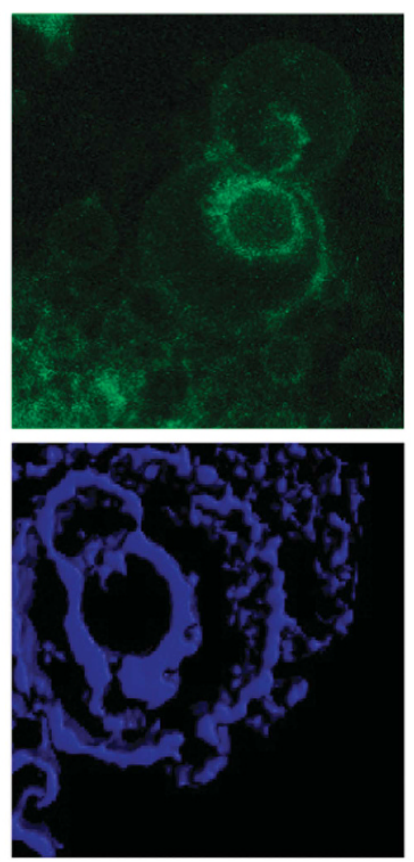
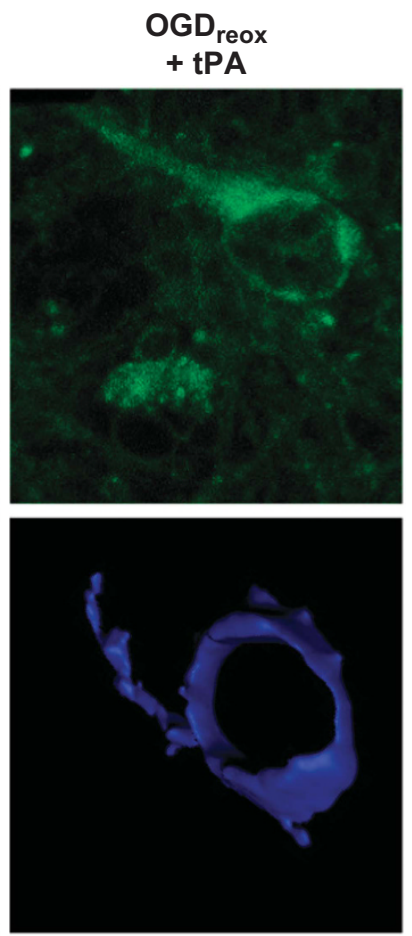

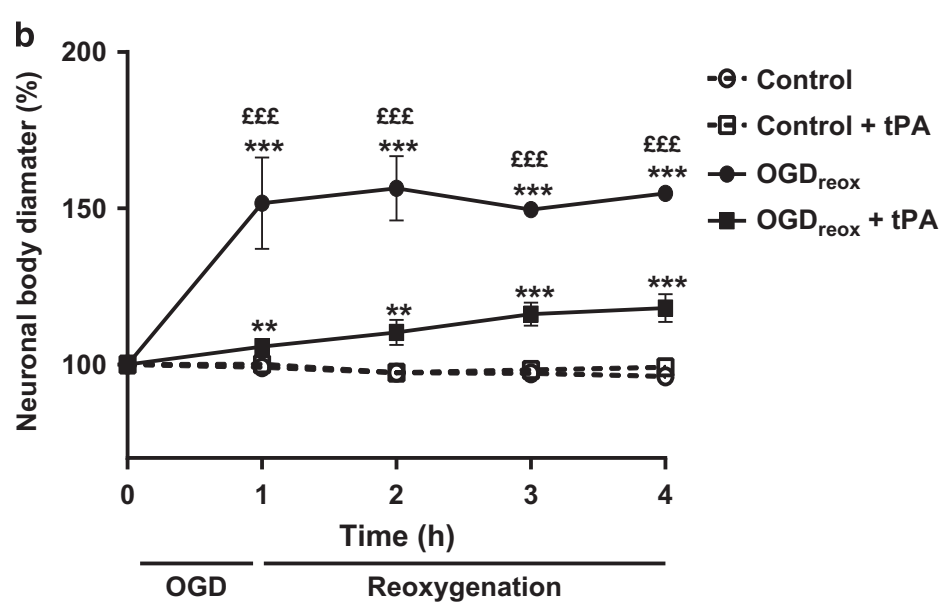

Figure 4 tPA preserves ER neuronal continuity after $O \mathrm{GD}_{\text {reox }}$ (a) Representative pictures of neurones labelled with ER-tracker (in green) and 3D construction (in blue) after $\mathrm{OGD}_{\text {reox }}(1 \mathrm{~h} \mathrm{OGD}+4 \mathrm{~h}$ of reoxygenation) or not and in the presence or not of $300 \mathrm{nM}$ tPA (scale bars, $5 \mu \mathrm{M}$ ). (b) Neuronal body diameter at different time (before OGD: t0; after $1 \mathrm{~h}$ of OGD: t1; and after $1 \mathrm{~h}: \mathrm{t} 2,2 \mathrm{~h}$ : $\mathrm{t} 3$ and $3 \mathrm{~h}$ : 44 of reoxygenation) in presence or not of $300 \mathrm{nM}$ tPA (data are represented as mean \pm S.E.M. $n=9$ independent experiments

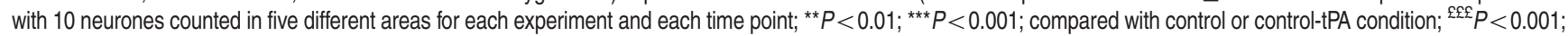
compared with OGD-tPA condition; Mann-Whitney tests)

Figure 3 tPA decreases the PERK branch of the UPR-mediated neuronal death under OGD reox conditions. (a) Diagram of the OGD reox protocol used on pure cortical neurones. Neurones were washed with OGD media and stayed under OGD conditions during $40 \mathrm{~min}$ followed by a $4 \mathrm{~h}$ reoxygenation period. (b) Representative immunostainings against phospho-elF2 $\alpha$ (in green) and NeuN (in blue) on cultured neurones subjected or not to 40 min of OGD $\pm 300 \mathrm{nM}$ tPA (representative images of three independent experiments; scale bar, $20 \mu \mathrm{m}$ ). (c) Representative western blots against phosphor- and total elF2 $\alpha$ after various time of OGD (10, 40 and $60 \mathrm{~min})$ followed by $4 \mathrm{~h}$ of reoxygenation, in the presence or not of $300 \mathrm{nM} \mathrm{tPA}$. (d) Corresponding ratio of the phosphorylated versus total form of elF2 $\alpha$ (data are represented as mean \pm S.E.M. $n=5$; ${ }^{\star} P<0.05$ versus Ctrl condition; ${ }^{\$} P<0.05$ between OGDreox conditions; ${ }^{£} P<0.05$ between OGDreox+tPA conditions; ${ }^{\%} P<0.05$ between OGDreox versus OGDreox+tPA conditions; Mann-Whitney test). (e) qPCR analyses of ATF4, CHOP, GADD34 and Grp78 after OGD reox in the presence or not of $300 \mathrm{nM}$ tPA (data are represented as mean $+/-$ S.E.M. $n=5 ;{ }^{*} P<0.05 ;{ }^{*} P<0.01$; Mann and Whitney test; $C N R Q$ : calibrated normalized relative quantities). ( $F$ ) Neuronal death assessed by $L_{D H}$ release after $O G D_{\text {reox }}$ in the presence or not of $300 \mathrm{nM}$ tPA (data are represented as mean \pm S.E.M. Ctrl: $n=32$; OGD: $n=28$; OGD+tPA: $n=32$; from four independent experiments. ${ }^{* \star} P<0.01$; ${ }^{* * \star} P<0.001$; Mann-Whitney test) 


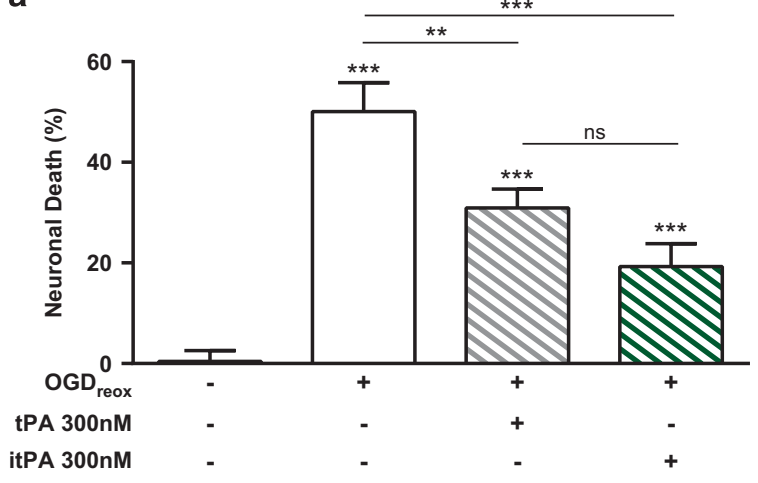

C

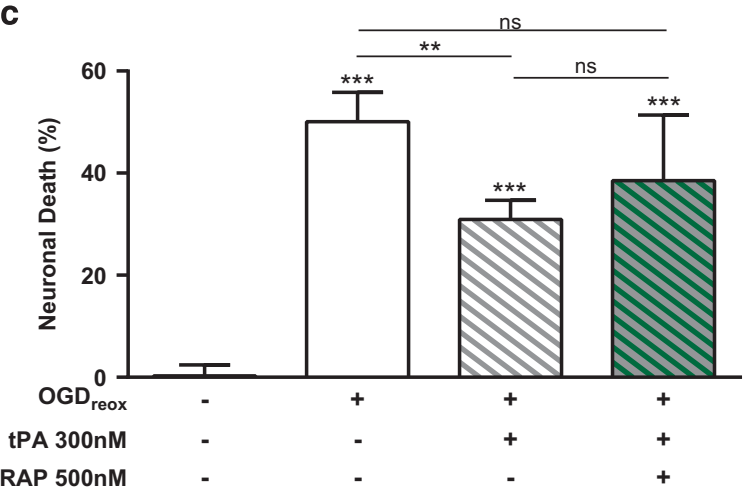

b

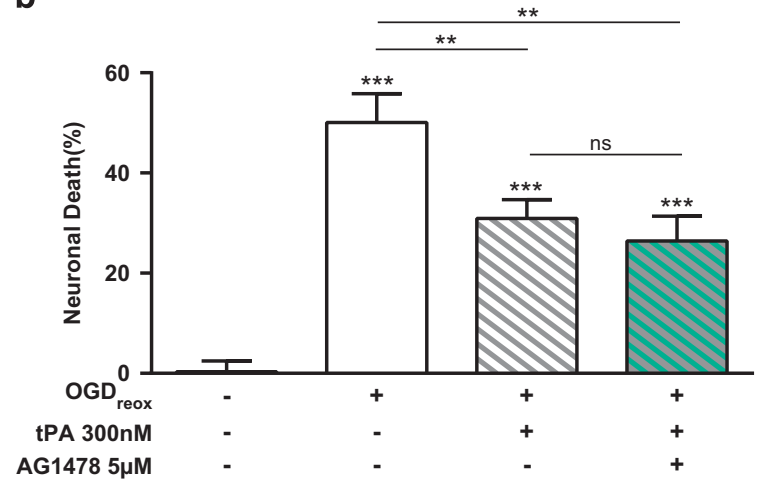

d

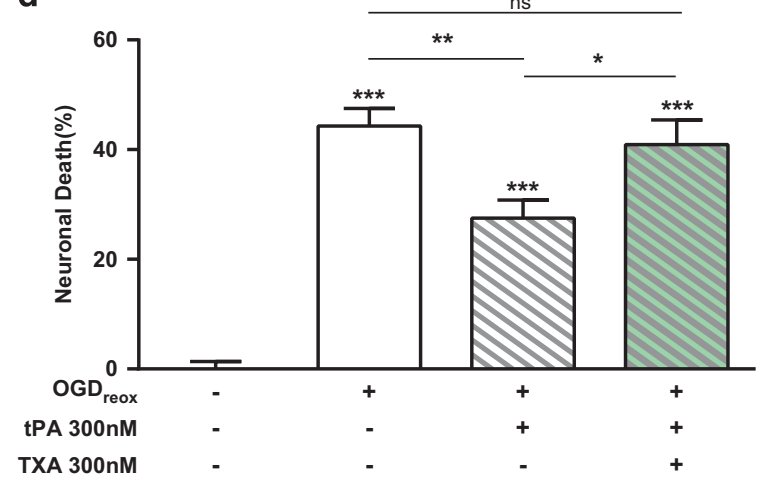

Figure 5 the LBS contained within the kringle 2 domain of tPA is involved in the decrease of the PERK branch of the UPR-mediated neuronal death during OGD ${ }_{\text {reox. }}$ (a) Neuronal death assessed by LDH release in the media after $40 \mathrm{~min}$ of OGD followed by $4 \mathrm{~h}$ of reoxygenation in the presence or not of $300 \mathrm{nM}$ tPA, or in the presence of inactive tPA (itPA) $300 \mathrm{nM}$. tPA was also tested in addition to AG1478 $5 \mu \mathrm{M}(\mathbf{b})$, RAP (500 nM) (c) and TXA $300 \mathrm{nM}$ (d), (data are represented as mean \pm S.E.M. $n=30$ for ctrl, $n=28$ for OGD, $n=32$ for tPA, $n=22$ for itPA, $n=18$ for AG1478, $n=12$ for RAP, $n=16$ for TXA; from four independent experiments; ${ }^{*} P<0.05 ;{ }^{* *} P<0.01 ;{ }^{* * *} P<0.001$; Mann-Whitney test)

revealed a Grp78 band (Figure 6b), confirming tPA as a ligand. Indeed, the interaction between tPA and cell surface Grp78 has been reported in neuroblastoma cells. ${ }^{29}$ The binding of tPA to Grp78 occurs on the amino acid sequence 98-115 (LIGRTWNDPSVQQDIKFL). ${ }^{29}$ We thus synthetized a corresponding competitive peptide called Grp78(98-115), and confirmed its competitive nature in a plasminogen-like fluorogenic substrate assay. Recombinant Grp78 7.3 pM (equimolar to tPA concentration) or 10 times concentrated increased tPA fibrinolytic activity by 25 and $40 \%$ respectively (Supplementary Figure 2A, $P<0.001$ ). Interestingly, a tPA mutated in its LBS contained within the kringle 2 domain (tPA K2*: W253R mutation) is no longer able to interact with Grp78, as shown by the absence of increased tPA K2* activity (Supplementary Figure $2 \mathrm{~B}$ ). When co-incubated with Grp78 $_{(98-115)}$ (7.3 or 73pM), Grp78 could no longer potentiate tPA fibrinolytic activity (Supplementary Figure 2A). A scramble peptide Grp78$_{(98-115) s c}$ had no action on the potentiation of tPA fibrinolytic activity by Grp78 (Supplementary Figure $2 \mathrm{~A} ; \quad P<0.01)$. We then ensured the capacity of Grp78$_{(98-115)}$ to decrease the binding of tPA to cell surface Grp78 in living neurones. ${ }^{35} \mathrm{~S}$ radiolabelled tPA (tPA*) was incubated on neurones after $40 \mathrm{~min}$ of OGD in the presence or not of $\operatorname{Grp} 78_{(98-115)}(10 \mu \mathrm{M})$ during $30 \mathrm{~min}$ at $4{ }^{\circ} \mathrm{C}$ (to avoid any active process of internalization). Our data demonstrate a decrease of $\mathrm{tPA}^{*}$ at the neuronal membrane in the presence of Grp78 $_{(98-115)}$ (Figure 6c, 49.2\% decreased with $\left.\operatorname{Grp78}_{(98-115)} ; P<0.001\right)$, confirming the ability of our peptide to decrease the binding between tPA and cell surface Grp78 in neurones. We then tested the blocking peptide under OGD reox conditions. After $40 \mathrm{~min}$ of $\mathrm{OGD}$ and $4 \mathrm{~h}$ of reoxygenation, Grp78 ${ }_{(98-115)}$ reversed tPA-mediated inhibition of the PERK branch, as shown by western blot against elF2a phosphorylation (Figure 6d) and the corresponding densitometries (Figure 6e; ratio of 1.02 between the phosphorylated and the total form of elF2 $a$ for tPA under OGD reox $; 1.52$ for tPA + Grp78$_{(98-115)}$ under OGD reox; $\left.P<0.05\right)$. Interestingly, Grp78 (98-115) totally reversed the neuroprotective effect of tPA in cortical neurones (Figure $6 f, 31 \%$ of neuronal death for tPA+Grp78 ${ }_{(98-115)}$ under OGD reox, $12 \%$ for tPA under $\left.O G D_{\text {reox }} ; P<0.01\right)$. To ensure our findings, we also tried the peptide on hippocampal slices subjected to $O G D_{\text {reox }}$. Grp78$_{(98-115)}$ also reversed tPA-mediated inhibition of the PERK branch as shown by western blot against elF2a phosphorylation (Figure $6 \mathrm{~g}$ and the densitometries Figure $6 \mathrm{~h}$; ratio of 1.02 between the phosphorylated and the total form of elF2 $a$ for tPA under OGD reox 1.52 for tPA+Grp78 ${ }_{(98-115)}$ under $\left.\mathrm{OGD}_{\text {reox }} ; P<0.05\right)$. Grp78 ${ }_{(98-115)}$ also prevented the protection by tPA on hippocampal slices subjected to OGD ${ }_{\text {reox }}$ (Figure $6 \mathrm{i}, 61 \%$ of protection for $\mathrm{tPA}$ under $\mathrm{OGD}_{\text {reox }}$, 
a

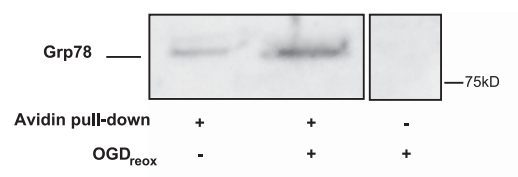

b

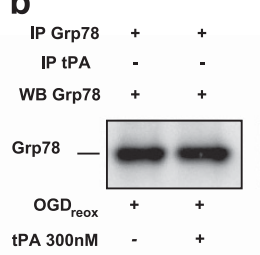

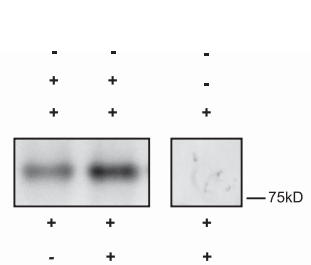

d

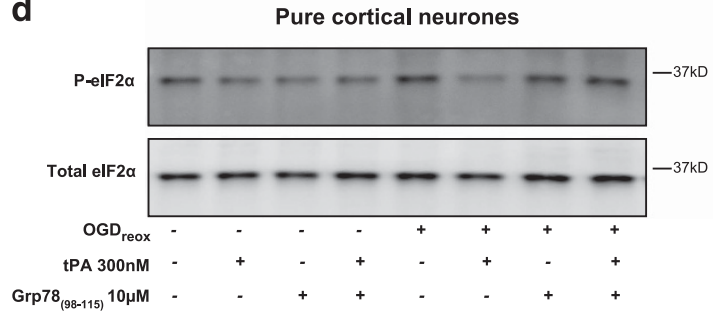

g

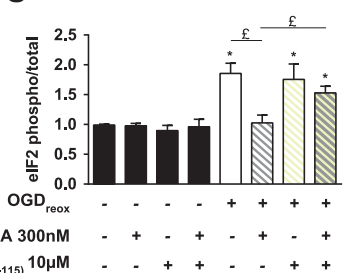

f

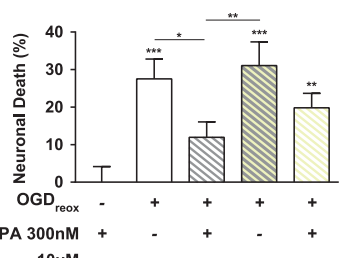

g

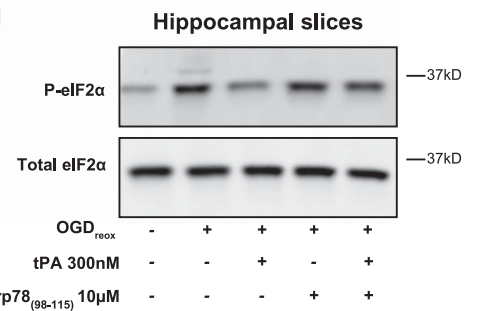

h

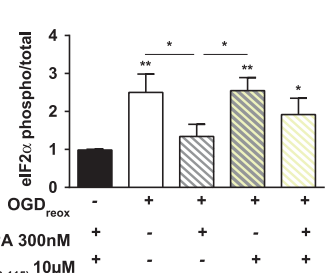

i

Figure 6 The interaction between IPA and cell surface Grp78 is responsible of the decrease of the PERK branch activation and the associated neuroprotection during $\mathrm{OGD}_{\text {reox}}$. (a) Avidin pull-down and western blot against Grp78 on neurones subjected or not to 40 min of OGD, followed by the biotinylation of membrane protein at $4{ }^{\circ} \mathrm{C}$ (representative blot from $n=3$ independent experiments). (b) Immunoprecipitations with either Grp78 or tPA antibodies on neurones subjected to 40 min of OGD, and revealed by western blot against Grp78 (representative blot of three independent experiments). (c) Membrane-bound radioactivity after radioactive tPA (tPA*) incubation ( 30 min) at $4{ }^{\circ} \mathrm{C}$ following a 40 min OGD period in presence or not of $10 \mu \mathrm{M}$ of Grp78(98-115) peptide (data are represented as mean ImmunoprecipitatioSEM $n=4$ independent experiments; ${ }^{* \star \star} P<0.001$ Mann-Whitney test). (d) Representative western blots against phosphor- and total elF2 $\alpha$ and corresponding densitometries (e) from pure cortical neurones subjected to $40 \mathrm{~min}$ of OGD followed by $4 \mathrm{~h}$ of reoxygenation, in the presence or not of $300 \mathrm{nM}$ tPA and $10 \mu \mathrm{M}$ Grp78(98-115) (data are represented as mean \pm S.E.M. $n=5$ independent experiments; * $P<0.05$ compared to normoxia; ${ }^{£} P<0.05$ compared between $O G D_{\text {reox }}$ conditions). (f) Neuronal death of pure cortical neurones assessed by $L D H$ release after $40 \mathrm{~min}$ of OGD followed by $4 \mathrm{~h}$ of reoxygenation in the presence or not of $300 \mathrm{nM} \mathrm{tPA}$ and $10 \mu \mathrm{M} \mathrm{Grp78}_{(98-115)}$ (data are represented as mean $\pm \mathrm{S}$.E.M. $n=25$ for ctrl, $n=20$ for $\mathrm{OGD}_{\text {reox }}, n=16$ for tPA, tPA+Grp78 $(98-115)$ and Grp78 $(98-115)$ from five independent experiments; ${ }^{*} P<0.05$; ${ }^{* *} P<0.01$; ${ }^{* * *} P<0.001$; Mann-Whitney test). (g) Representative western blots against phospho- and total eIF2 $\alpha$ on hippocampal slices subjected to $40 \mathrm{~min}$ of OGD followed by $24 \mathrm{~h}$ of reoxygenation, in the presence or not of $300 \mathrm{nM} \mathrm{tPA}$ and $10 \mu \mathrm{M}$ Grp78 ${ }_{(98-115)}$ and corresponding ratio of the phosphorylated versus total form of elF2 $\alpha(H)$ (data are represented as mean \pm S.E.M. $n=6$; ${ }^{*} P<0.05$; ${ }^{* *} P<0.01$; Mann-Whitney test). (i) Cell death assessed by counting of propidium iodide-positive cells in slices $24 \mathrm{~h}$ after treatments and normalized to the $O \mathrm{GD}_{\text {reox }}$ condition in the presence or not of $300 \mathrm{nM} \mathrm{tPA}$ and $10 \mu \mathrm{M}$ Grp78(98-115) (data are represented as mean \pm S.E.M. $n=12$ from four independent experiments; ${ }^{*} P<0.05,{ }^{* *} P<0.01$, ${ }^{* \star *} P<0.001$, Mann-Whitney test)

totally reversed with the co-application of Grp78 $_{(98-115)}$, $\left.{ }^{\star \star} P<0.01\right)$. Again, this effect was associated with a reversion of the inhibition of elF2a phosphorylation by tPA (Figure $6 \mathrm{~g}$ and $h$, ratio of 1.34 between the phosphorylated and the total form of elF2 $a$ for tPA under OGD reox, 2.55 for $\mathrm{tPA}+\mathrm{Grp78}_{(98-}$ 115) under $\left.\mathrm{OGD}_{\text {reox }} ; P<0.05\right)$. Taken together, these data show that modulating cell surface Grp78 during intense ER stress is a new and interesting therapeutic target to prevent cell death from deleterious ER stress.

\section{Discussion}

In this study, we demonstrate for the first time that the binding of tPA to cell surface Grp78, triggers a signal that decreases detrimental ER stress overactivation in neurones, resulting in neuroprotection. We also show that ischaemic events lead to the translocation of the chaperone Grp78 from the ER to the neuronal surface, a mechanism described under ER stress activation and in cancer. ${ }^{27,28}$ Interestingly, the serine protease
tPA is able to bind to cell surface Grp78 leading to a decrease of the PERK/elF2 $a$ axis of the UPR, and resulting in neuronal survey during cerebral ischaemia.

To study ER stress activation, we first subjected CAREluciferase mice to thromboembolic ischaemia, alone or coupled to reperfusion by IPA in the same conditions than its clinical use. ${ }^{19}$ We observed a strong activation of the elF2aATF4 pathway after ischaemic stroke, a surrogate marker of the activation of the PERK-eIF2 $a$ branch of the UPR. Indeed, while kinases other than PERK can phosphorylate elF2a (GCN2 (general control nonderepressible 2), HRI (haemregulated elF2a kinase) and PKR (Protein kinase RNAactivated), studies in genetically deficient mice revealed that during cerebral ischaemia, PERK is the only kinase responsible for elF2 $a$ phosphorylation. ${ }^{30,31}$

We also demonstrated an increase of cell surface Grp78 at the neuronal surface after $O G D_{\text {reox }}$ (Figure 6a). Grp78 is mostly known as an ER chaperone, belonging to the heatshock protein family, but it has also been described at the cell 
surface of cancer cells, ${ }^{29,32}$ macrophages, ${ }^{27}$ endothelial cells, ${ }^{33,34}$ and cardiomyocytes. ${ }^{32}$ Accordingly, Grp78 is now recognized as a receptor/co-receptor for different partners, including activated a2-macroglobulin, ${ }^{35}$ plasminogen/ microplasminogen, ${ }^{36}$ some viruses, ${ }^{37,38}$ major histocompatibility complex class $\mathrm{I}^{38}$ and voltage-dependent anion channels. ${ }^{36}$ Grp78 has also been shown to interact with tPA, resulting in an increase in plasmin formation. ${ }^{29}$ Here, we demonstrate the presence of cell surface Grp78 in neurones, and we confirm the occurrence of the interaction between Grp78 and recombinant tPA (Figure 6b), but extend its functional impact to neuroprotection. To our knowledge, Grp78 has no intrinsic ability to convey intracellular signals, as demonstrated by analyses of its sequence and hydropathicity. ${ }^{27}$ Rather, Grp78 would need co-receptors. ${ }^{27}$ In our study, none of the classical neuronal receptors of tPA (NMDA receptor, LRP1, EGFR) seem to be involved in the effect observed (Figure 5).

Hypoxia/ischaemia ${ }^{39}$ or ER stress ${ }^{28,32}$ are known triggers of Grp78 translocation. However, how Grp78 translocates from the ER to the cell membrane remains unclear. In 293 T cells, thapsigargin treatment leads to a 12-fold increase of cell surface Grp78 that is different from its increase within the $\mathrm{ER}^{32}$ suggesting that ER stress promotes specific mechanism(s) to enhance cell surface localization of Grp78. Importantly, Grp78 is brought to the cell surface by a specific mechanism, as extracellular Grp78 originating from dead cells cannot stably attach to the cell surface. ${ }^{32}$ In addition, a same signal induces or not Grp78 translocation in different cells. For instance, hypoxia enhances Grp78 at the membrane of neurones but not of astrocytes. ${ }^{39}$

Our study also describes a new role for the serine protease tPA. It remains the gold standard treatment for cerebral ischaemia despite its short therapeutic window. ${ }^{40,41}$ But since several years, it is clearly admitted that tPA is more than a vascular enzyme with many roles in the cerebral physio pathology. ${ }^{20}$ tPA has first been described as a pro-excitotoxic protein, ${ }^{42}$ mainly by interacting with the GluN1 subunit of the NMDA receptor. ${ }^{43}$ In the meantime, it has also been shown that cerebral tPA was anti-apoptotic. ${ }^{44}$ Things seem more complex, as depending of its form, its dose, and its localization tPA can display pro-survival effects on neurones. ${ }^{21,45}$ For example, tPA is neuroprotective in a model of glucose privation $^{46}$ and a model of cerebral ischaemia, ${ }^{47}$ and this effect required NMDA receptors. At the first look, it could seem contradictory with previous findings where tPA interaction with NMDA receptors was detrimental in stroke. ${ }^{43,48}$ But in fact it seems that protective effects of tPA are mediated by the activation of synaptic NMDA receptors, ${ }^{47}$ while its activation of extrasynaptic receptors leads to excitotoxicity. ${ }^{49}$ Here, we identified cell surface Grp78 as a new neuronal receptor of tPA. It's binding leads to negative feedback on the PERK branch activation, resulting in less elF2 $a$ phosphorylation, and more importantly less CHOP induction, so less death during ischaemic events. Importance of Grp78 is confirmed by studies using AdoPep1, a peptide identified in the metalloproteinase domain of a disintegrin and metalloproteinase 15 protein (ADAM15), that binds to cell surface Grp78 and inhibits hypoxia-induced apoptosis in endothelial cells and increases Akt phosphorylation and ERK $1 / 2$ activation. ${ }^{34}$ Moreover,
AdoPep1 also inhibits hypoxia-induced apoptosis in cardiomyocytes and protects cardiac cells during myocardial ischaemia, ${ }^{50}$ and also prevents pancreatic $\beta$-cells from type 1 diabetes-induced apoptosis. ${ }^{51}$ Another compound, BIX (BiP Inducer X), is able to induce the expression of Grp78 through the ATF6 pathway. ${ }^{52}$ BIX has been shown to protect neuroblastoma cells from ER stress-induced cell death and to decrease infarct size in rodents following various models of cerebral ischaemia. ${ }^{52,53}$ However, none of these studies have investigated the precise localization of the protein.

Overall, we describe here for the first time a PERK-elF2anegative feedback due to the activation of cell surface Grp78 by the serine protease tPA. We confirm the translocation of Grp78 from the ER to the neuronal surface, and we validate tPA as a ligand of Grp78. We demonstrate that tPA activation of cell surface Grp78 is capable to mediate beneficial effects on ER stress during cerebral ischaemia independently of its thrombolytic activity. Taken altogether, Grp78 represents an original therapeutic target to decrease the deleterious effects associated to ER stress.

\section{Material and Methods}

Reagents. Dulbecco's modified eagle's medium (DMEM), poly-D-lysine, cytosine $\beta$-D-arabinoside, fetal bovin serum, horse serum, D-glucose, trans- $\mathrm{N}_{1} \mathrm{~N}^{\prime}-1$, 4-Cyclohexanediylbis[2-(4-chlorophenoxy)-acetamide (ISRIB), propidium iodide, tween-20, phosphatase inhibitor cocktail, protease inhibitor cocktail, guanabenz, Tris- $\mathrm{HCl}, \mathrm{NaCl}$, Triton-100X paraformaldehyde, sucrose, TRI reagent, hygromycin B, diisopropylethylamine (DIEA), piperidine, trifluoroacetic acid (TFA) and murine thrombin were from Sigma-Aldrich (Saint-Quentin-Fallavier, France). Beetle luciferin substrate was from Promega (Lyon, France). Glutamine, laminin, glucose-free DMEM, Roswell Park Memorial Institute 1640 medium (RPMI), MEM, Lipofectamine 2000, RIPA buffer, Pierce ECL Plus and M-MLV Reverse transcriptase were purchased from Fisher (Illkirch-Graffenstaden, France). AG1478 (N-(3-Chlorophenyl)-6,7-dimethoxy-4-quinazolinanine hydrochloride ) was purchased from Tocris (Bristol, UK). Bicinchoninic acid assay (BCA Protein Assay kit) was purchased from Pierce (Rockford, IL, USA). Human recombinant IPA (rtPA actilyse) was from Boehringer Ingelheim (Pacé, France). Human Receptor Associated Protein (RAP) was from Gentaur (Paris, France). 1,5-Dansyl-L-glutamyl-L-glycyl-L-arginine chloromethylketone (dGGACK) and Salubrinal were from Calbiochem (Nottingham, UK). Fmoc-L-amino acid residues were purchased from Senn Chemicals (Dielsdorf, Switzerland). The preloaded 4-hydroxymethyl-phenoxymethyl-copolystyrene-1\%divinylbenzene (HMP) resins and O-benzotriazol-1-yl- $N, N, N^{\prime}, N^{\prime}$-tetramethyluronium hexafluorophosphate (HBTU) were purchased from Life Technologies (Villebon-surYvette, France). Acetonitrile and $\mathrm{N}$-methylpyrrolidone (NMP) were from Biosolve Chimie (Dieuze, France).

Thromboembolic model of stroke. Experiments were performed in accordance with French laws (act no. 87-848; Ministère de l'Agriculture et de la Forêt) and European Communities Council Directives of November 24, 1986 $(86 / 609 / \mathrm{EEC})$ guidelines, and have been approved by the local ethical committee. Experiments were performed following the ARRIVE guidelines (www.nc3rs.org.uk), including randomization and blind analyses. Mice were deeply anaesthetised with $5 \%$ isoflurane (Baxter, Paris, France, in a mixture of $\mathrm{N}_{2} \mathrm{O} / \mathrm{O}_{2}$ ), placed in a stereotaxic device and maintained under anaesthesia for up to $2 \mathrm{~h}$ with $2 \%$ isoflurane in a 70/30 mixture of $\mathrm{N}_{2} \mathrm{O} / \mathrm{O}_{2}$. Through a skin incision between the right eye and ear, the masseter muscle was excised, and a small craniotomy (diameter $1 \mathrm{~mm}$ ) was performed on the parietal bone to expose the right middle cerebral artery. Thromboembolic stroke was induced as previously described. ${ }^{19}$ Briefly, craniotomy was performed by using cooled drill, then the dura was excised and a pipette filled with murine thrombin $(1 \mathrm{UI} / \mu \mathrm{L})$ was directly inserted in the MCA lumen. One microliter of thrombin was injected to induce thrombus formation. Thrombolysis was induced by intravenous IPA (actilyse $10 \mathrm{mg} / \mathrm{kg}$ ) administration (10\% bolus, $90 \%$ over $40 \mathrm{~min}) 20 \mathrm{~min}$ after clot onset. Control animals received intravenous saline injection in the same conditions, and sham animals only had the surgical approach. 
Bioluminescence imaging. CARE-Luciferase mice expressing the luciferase reporter gene under the control of the thymidine kinase promoter activated by two Trb3 (tribbles pseudokinase 3) sequences containing the three CARE (C/EBP (CCAAT/enhancer binding protein)-ATF response element) sequences of recognition (black circles on Supplementary Figure $3 \mathrm{~A}$ ) were previously described. ${ }^{18}$ Control experiments were performed after a local injection of tunicamycin (a well-known inducer of ER stress, $0.05 \mu \mathrm{g} / \mathrm{g}$ ) in their abdomen. As expected, the luciferase signal measured $6 \mathrm{~h}$ after the injection of tunicamycin was increased by 20 -fold when compared to control non-injected mice (representative images Supplementary Figure $3 \mathrm{~B}$ and corresponding means Supplementary Figure $3 C ; n=6 ; P<0.01$ ).

Post-stroke bioluminescence imaging was performed using the IVIS Spectrum (PerkinElmer, Villebon-sur-Yvette, France) imaging scanner coupled to the Living Image Software (PerkinElmer). Briefly, $100 \mathrm{mg} / \mathrm{kg}$ of in vivo luciferase substrate (beetle luciferin substrate, Promega) were injected intraperitoneally into each CARELuciferase mouse. Mice were then anaesthetised with isofluorane- and scanned $10 \mathrm{~min}$ after luciferin injection. The abdominal cavity was shaved to allow accurate collection of bioluminescence signals. Light emission was quantified with imaging software from constant regions of interest (ROI) drawn manually. Photon emission was measured as radiance in ps-1cm-2sr-1. The sensitivity of the imaging scanner was tested weekly with commercially available positive sources of bioluminescence. Excised brains were imaged immediately after euthanasia using the IVIS Spectrum (PerkinElmer) imaging scanner coupled to the Living Image software (PerkinElmer).

Luciferase biochemical assay. Luciferase assays were performed as previously described. ${ }^{54}$ Luciferase activities measured in brain extracts were normalized to protein content (RLU/mg protein) and expressed as fold induction relative to the control condition.

Organotypic hippocampal slice cultures. Seven-day-old mouse pups of either sex were decapitated and their brain collected in PBS containing $5 \mathrm{mg}$ of glucose. Hippocampal slices $(400 \mu \mathrm{m})$ were prepared using a Mcllwain tissue chopper (Brinkmann Instruments, World Precision Instruments, Hitchin, UK) and placed on $0.4 \mu \mathrm{m}$ Millicell culture inserts (Millipore, Guyancourt, France), as previously described. ${ }^{24}$ Slices were maintained in a humidified incubator with $5 \%$ $\mathrm{CO}_{2}$ at $37^{\circ} \mathrm{C}$ with $1 \mathrm{ml}$ of MEM containing $20 \%$ horse serum, supplemented with $10 \mathrm{mM}$ HEPES and insulin, $\mathrm{pH}$ 7.2-7.3.

Neuronal cell cultures. Primary cultures of cortical neurones were prepared from foetal mice (embryonic day 14 ) as previously described. ${ }^{55}$ Cells were cultured on individual glass bottom Petri dishes (MatTek Corporation, Ashland, MA, USA) or 24-well plates, previously coated with poly-D-lysine $(0.1 \mathrm{mg} / \mathrm{ml})$ and laminin $(0.02 \mathrm{mg} / \mathrm{ml})$, in DMEM supplemented with $5 \%$ foetal bovine serum, $5 \%$ horse serum and $1 \mathrm{mM}$ glutamine. Cultures were maintained at $37^{\circ} \mathrm{C}$ in a humidified $5 \%$ CO2 atmosphere. Cytosine $\beta$-D-arabinoside $(10 \mu \mathrm{M})$ was added after 3 days in vitro (DIV) to inhibit glial proliferation in the 24-well plates. Oxygen and glucose deprivation was performed after 11-12 DIV.

Oxygen and glucose deprivation (OGD). Hippocampal slices (7 DIV) or neuronal cultures (11-12 DIV) were subjected for various times to OGD in a hypoxic chamber (IN VIVO2 500; Ruskinn, AWEL International, Blain, France) programmed at $1 \% \mathrm{O}_{2}, 5 \% \mathrm{CO}_{2}$ and $37^{\circ} \mathrm{C}$ in glucose/serum-free deoxygenated DMEM. For reoxygenation, media were switched to oxygenated DMEM completed with D-glucose $(4.5 \mathrm{mg} / \mathrm{l})$ under normoxic conditions. Controls were subjected to sham washes.
Neuronal death. For hippocampal slices, neuronal death was assessed $24 \mathrm{~h}$ after reoxygenation by propidium iodide fluorescence. Propidium iodide $(50 \mu \mathrm{g} / \mu \mathrm{l})$ was added for $30 \mathrm{~min}$ in the medium, washed in PBS and then immersed in fixative buffer during $1 \mathrm{~h}$ ( $4 \%$ of paraformaldehyde in $0.1 \mathrm{M} \mathrm{PBS}, \mathrm{pH} 7.4$ ). Images were digitally captured using a Leica SP5 confocal microscope (Leica Microsystems SAS, Nanterre, France) and visualized with LAS AF lite software (Leica) and further quantified using ImageJ $1.45 \mathrm{r}$ software (National Institute of Health, Bethesda, MD, USA).

For cortical neurones, neuronal death was quantified $4 \mathrm{~h}$ after reoxygenation by measuring the lactate dehydrogenase activity released from damaged cells into the bathing medium with a cytotoxicity detection kit (Roche Diagnostics, Meylan, France).

Immunoblotting. Cells were dissociated in ice-cold TNT buffer $(50 \mathrm{mM}$ Tris$\mathrm{HCl} \mathrm{pH} \mathrm{7.4;} 150 \mathrm{mM} \mathrm{NaCl}$; 0.5\% Triton X-100; phosphatase and protease inhibitors cocktails) and centrifuged $\left(12,000 \mathrm{~g}, 4^{\circ} \mathrm{C}, 15 \mathrm{~min}\right)$. Protein concentration was measured by BCA Protein Assay method. Proteins $(20 \mu \mathrm{g})$ were resolved on a 10\% SDS-PAGE gel (Bio-rad, Marnes-la-Coquette, France) and transferred onto a polyvinylidene difluoride membrane. Membranes were blocked with $\mathrm{PBS}+0.1 \%$ tween-20,5\% milk and incubated overnight at $4{ }^{\circ} \mathrm{C}$ in blocking buffer containing primary antibodies. The following primary antibodies and dilutions were used: mouse anti-elf2 $\alpha$ (1/1000; Cell Signaling L57A5; Ozyme, Montigny-le-Bretonneux France), rabbit anti-Phospho-elf2 $\alpha$ (1/1000 Cell Signaling 119A11), goat anti-tPA (1/1000; sc5239; Santa-Cruz, Heidelberg, Germany). Membranes were then incubated with the corresponding peroxidase-conjugated secondary antibodies (1/25000; Sigma-Aldrich) in blocking buffer, and visualized with an enhanced chemiluminescence Pierce ECL Plus kit.

Quantitative real-time PCR. Total RNA was isolated from neuronal culture with TRI reagent according to the manufacturer instructions. Total RNA was treated with TURBO DNase (Ambion, Saint Aubin, France) to avoid DNA contamination and quantified by spectrophotometry (NanoDrop Technologies, Wilmington, DE, USA). One $\mu \mathrm{g}$ of total RNA was reverse-transcribed by using the M-MLV Reverse transcriptase according to the manufacturer's instructions with the following cycle conditions: $42^{\circ} \mathrm{C}(90 \mathrm{~min}) ; 85^{\circ} \mathrm{C}(5 \mathrm{~min})$. RT-qPCR was performed from 1:20 diluted CDNA in iQ SYBR Green Supermix (Bio-Rad; Marnes-la-Coquette, France) containing $500 \mathrm{nM}$ of each primer. Based on mRNA-coding sequences (www. ensembl.org), mouse-specific primers were designed by using the Primer3Plus software (http://www.bioinformatics.nl/cgi-bin/primer3plus/ primer3plus.cgi) ${ }^{56}$ (sequences are in Table 1). Assays were run in triplicate on the CFX96 real-time system c1000 thermal cycler (Bio-Rad), with the following cycle conditions: $95{ }^{\circ} \mathrm{C}$ (3 min); $\left(95^{\circ} \mathrm{C}(2 \mathrm{~s}), 60^{\circ} \mathrm{C}(20 \mathrm{~s})\right) \times 39 ; 70^{\circ} \mathrm{C}(30 \mathrm{~s})$. Normalization was performed according to the results of the geNorm analysis (QBase+ software, Biogazelle, Zwijnaarde, Belgium) (Supplementary Figure 4) as previously described. ${ }^{57}$

Immunohistochemistry. Twenty-four hours after ischaemia mice were deeply anaesthetised and transcardially perfused with $0.9 \% \mathrm{NaCl}$ heparinized followed by a mixture of $4 \%$ paraformaldehyde in $0.1 \mathrm{M} \mathrm{PBS}, \mathrm{pH} 7.4(150 \mathrm{ml})$. Brains were removed, washed in PBS buffer containing $20 \%$ sucrose and frozen in Tissue-Tek (Miles Scientific, Naperville, IL, USA). Coronal sections $(10 \mu \mathrm{m})$ were cut on a cryostat (Leica CM3050, Leica Microsystems SAS), collected on poly-Dlysine slides, and stored at $-80^{\circ} \mathrm{C}$. Sections were incubated overnight at room temperature with a goat anti-luciferase antibody (1/200; ab81823, Abcam, Cambridge, UK). The secondary $F(a b$ ')2 coupled to fluorescein isothiocyanate (FITC; 1:600; Jackson ImmunoResearch, West Grove, PA, USA) was used for visualization under epifluorescence. Washed sections were coverslipped with

Table 1 qPCR primer sequences

\begin{tabular}{lll}
\hline Name & Primer (5'-3') & Forward (5'-3') \\
\hline ATF4 & TCCTGAACAGCGAAGTGTTG & ACCCATGAGGTTTCAAGTGC \\
CHOP & CGTTCCTGGGGATGAGATA \\
GADD34 & CTGCCTTCACCTTGGAGAC & CTTCGATCTCGTGCAAACTG \\
Grp78 & AGGACCCCGAGATTCCTCTA & GGGGACAAACATCAAGCAGT \\
ActinB & ATAAACCCCGATGAGGCTGT & TACAGCCCGGGGAGCATCGT \\
RPII3A & GCAGCTCCTTCGTTGCCGGT & GGGAGGGGTGGTATCATC
\end{tabular}

Abbreviation: qPCR, quantitative PCR. 
antifade medium containing DAPI. Sections were examined with a microscope (DM6000; Leica Microsystems SAS). Images were digitally captured using a camera (Flash 4.0, Hamamatsu, Iwata, Japan). Images were visualized with Metamorph software (Molecular Devices, Sunnyvale, CA, USA).

Immunocytochemistry. After a brief wash in PBS, neuronal cultures grown on glass bottom Petri dishes were fixed during 5 min in 0.1 M PBS containing $4 \%$ paraformaldehyde and $5 \%$ sucrose. After PBS washes, cells were blocked for $1 \mathrm{~h}$ in PBS-Tween $200.1 \%$ containing $1 \%$ BSA and then incubated overnight at $4{ }^{\circ} \mathrm{C}$ in blocking buffer containing primary antibodies (rabbit anti-Phospho-elf2 $\alpha$; 1/50; Cell Signaling \#3597, Ozyme; mouse anti-NeuN (Fox3); 1/50; Millipore \#MAB377). Primary antibodies were revealed using FITC-coupled secondary F(ab') 2 (1: 600; Jackson ImmunoResearch). Confocal laser-scanning microscopy was performed using a Leica SP5 confocal microscope (Leica Microsystems SAS).

ER tracker. Cortical neurones in glass bottom Petri dishes at 11 DIV were loaded ( $30 \mathrm{~min}$ at $37^{\circ} \mathrm{C}$ ) with ER Tracker Blue ( $10 \mu \mathrm{M}$ Molecular Probes) before OGD, then washed with fresh serum-free DMEM and observed with LEICA SP5 confocal microscope (Leica Microsystems SAS), visualized with LAS AF lite software (Leica) and analysed with ImageJ $1.45 \mathrm{r}$ software (NIH) or Imaris software (Bitplane, Zurich, Switzerland).

Peptide synthesis. Grp78 (Leu ${ }^{98}$-Leu $^{115}$ ) (Grp78 ${ }_{(98-115)}$; LIGRTWNDPSVQGDIKFL) and scramble (Grp78 ${ }_{(98-115) s c ;}$ GTNKSQDLWIPQLRDVFI) peptides were synthesized ( $0.1 \mathrm{mmol}$ scale) on Fmoc-Leu-HMP and Fmoc-lle-HMP resins, respectively, using an Applied Biosystems model 433A automatic peptide synthesizer (Life Technologies; Villebon-sur-Yvette, France) and the standard procedures, as previously described. ${ }^{58,59}$ All Fmoc-amino acids (1 mmol, 10 eq.) were coupled by in situ activation with HBTU $(1.25 \mathrm{mmol}, 12.5$ eq.) and DIEA (2.5 mmol, 25 eq.) in NMP. Reactive side-chains were protected as follows: Arg, pentamethyldihydrobenzofuran (Pbf) sulfonylamide; Asn and Gln, trityl (Trt) amide; Ser, Thr and Tyr, tert-butyl (tBu) ether; Asp and Glu, O-tert-butyl (OtBu) ester; Lys and Trp, tert-butyloxycarbonyl (Boc) carbamate. Peptides were deprotected and cleaved from the resin by trifluoroacetic acid (TFA) as previously described. ${ }^{60}$ Crude peptides were purified by reversed-phase HPLC (RP-HPLC) on a Vydac 218TP1022 C18 column $(2.2 \times 25 \mathrm{~cm}$; Grace Discovery Sciences Alltech, Templemars, France) using a linear gradient $(10-60 \%$ over $60 \mathrm{~min}$ for Grp78 115)sc; $10-50 \%$ over $55 \mathrm{~min}$ for Grp78 $8_{(98-115)}$ of acetonitrile/TFA (99.9:0.1, v/v) at a flow rate of $10 \mathrm{ml} / \mathrm{min}$. Peptides were analysed by RP-HPLC on a Vydac 218TP54 C18 column $(0.46 \times 25 \mathrm{~cm}$; Grace Discovery Sciences Altech) using a linear gradient (10-60\% over $25 \mathrm{~min}$ ) of acetonitrile/TFA $(99.9: 0.1, \mathrm{v} / \mathrm{v})$ at a flow rate of $1 \mathrm{ml} / \mathrm{min}$. The purity of peptides was higher than $99.9 \%$. Peptides were characterized by MALDI-TOF mass spectrometry on a Voyager DE-PRO (Applera, France) in the reflector mode with $\alpha$-cyano-4-hydroxycinnamic acid as a matrix.

Production of radioactive tPA. A human TPA pcDNA5/FRT vector was constructed using a PCR strategy from the pUC19-HutPA vector kindly gifted by Prof. HR Lijnen and checked by automating sequencing. HEK-FIpln cells (Life Technologies), grown in RPMl 1640 medium supplemented with $10 \%$ foetal bovine serum and $2 \mathrm{mM}$ glutamine, were transfected with Lipofectamine 2000. Positive clones were isolated by hygromycin $B$ selection. The quality of the transfection was assessed by quantitative RT-PCR. Transfected HEK cells were grown T300 flasks in the presence of radioactive medium mix (RPMI- 1640 medium, $5 \%$ foetal bovine serum, $2 \mathrm{mM}$ glutamine, EXPRESS Protein Labelling Mix containing 35Smethionine and 35S-cysteine) during 7 days. Radioactive IPA (tPA*) secreted in the supernatants was purified using a nickel-nitrilotriacetic acid metal-affinity chromatography matrix (Qiagen, Courtaboeuf, France). tPA* was then conditioned in HEPES buffer $(0.35 \mathrm{M}, \mathrm{pH} 7.4)$ and stored at $-20^{\circ} \mathrm{C}$. Immunoblottings to check tPA production were performed using a polyclonal sheep antiserum raised against human IPA (1:5000) prepared at the National institute for agronomic research (INRA, Clermont-Theix, France), followed by incubation with the appropriate peroxydase-conjugated secondary antibody (Supplementary Figure 5A). Immunoblots were revealed with an enhanced chemoluminescence ECL Plus immunoblotting detection system (PerkinElmer-NEN, Paris, France). To ensure the incorporation of radioactivity, the blotting membrane was revealed by autoradiography by using Cyclone Imager (PerkinElmer) (Supplementary Figure 5B). Importantly, the procedure did not alter the enzymatic amidolytic activity of $\mathrm{PA}^{*}$, as evidenced by a fluorogenic assay (Spectrofluor FL444, American Diagnostica, Neuville sur Oise, data not shown).
Immunoprecipitation. Cells were lysed in RIPA buffer and lysates were pre-cleared with goat $\operatorname{lgG}$ bound to $50 \%$ (v/v) Protein G-Sepharose for $1 \mathrm{~h}$ at $4{ }^{\circ} \mathrm{C}$. Grp78 or tPA were immunoprecipitated overnight at $4^{\circ} \mathrm{C}$ with specific antibodies pre-bound to protein G-sepharose (50\% (v/v) protein G-sepharose plus $1 \mu \mathrm{g}$ of purified antibody at $4{ }^{\circ} \mathrm{C}$ for $2 \mathrm{~h}$ ). The following day, immunocomplexes were washed four times with cold PBS and once with RIPA buffer. Immunocomplexes proteins were recovered in SDS-PAGE loading buffer by heating for $5 \mathrm{~min}$ at $90^{\circ} \mathrm{C}$, separated on $10 \% \mathrm{w} / \mathrm{v}$ gel and detected by western blot analysis using antibodies against Grp78 (goat anti-Grp78; $200 \mu \mathrm{g} / \mathrm{ml}$; Santa Cruz \#SC1050).

tPA proteolytic activity assay. tPA* was incubated in the presence of a fluorogenic substrate $(5 \mu \mathrm{M})$ (Spectrofluor FL444, American Diagnostica). The reaction was carried out at $37^{\circ} \mathrm{C}$ in $50 \mathrm{mM}$ Tris (pH 8.0) containing $150 \mathrm{mM} \mathrm{NaCl}$ in a total volume of $100 \mu \mathrm{l}$. The amidolytic activity was measured as the change in fluorescence emission at $440 \mathrm{~nm}$ (excitation at $360 \mathrm{~nm}$ ).

Statistics. Mean \pm S.E.M. were represented on graphs, and analysed with the Mann-Whitney test (GraphPad Prism software).

\section{Conflict of Interest}

The authors declare no conflict of interest.

Acknowledgements. This project was supported by the Region BasseNormandie and the AXA postdoctoral fellowship program, the INSERM, and the university of Caen. We thank Mr Gilbert Pigrée and Mr Maxime Lemarchand for their help with the production of radioactive IPA (IMOGERE platform, University of Caen, France). Thanks to Dr Mario Gonzalez-Gronow for the gift of recombinant Grp78.

1. Ron $D$, Walter $P$. Signal integration in the endoplasmic reticulum unfolded protein response. Nat Rev Mol Cell Biol 2007; 8: 519-529.

2. Walter $P$, Ron $D$. The unfolded protein response: from stress pathway to homeostatic regulation. Science 2011; 334: 1081-1086.

3. Szegezdi E, Logue SE, Gorman AM, Samali A. Mediators of endoplasmic reticulum stressinduced apoptosis. EMBO Rep 2006; 7: 880-885.

4. Roussel BD, Kruppa AJ, Miranda E, Crowther DC, Lomas DA, Marciniak SJ. Endoplasmic reticulum dysfunction in neurological disease. Lancet Neurol 2013; 12: 105-118.

5. Harding HP, Zhang Y, Ron D. Protein translation and folding are coupled by an endoplasmicreticulum-resident kinase. Nature 1999; 397: 271-274.

6. Marciniak SJ, Garcia-Bonilla L, Hu J, Harding HP, Ron D. Activation-dependent substrate recruitment by the eukaryotic translation initiation factor 2 kinase PERK. J Cell Biol 2006; 172: 201-209.

7. Harding HP, Zhang Y, Zeng H, Novoa I, Lu PD, Calfon M et al. An integrated stress response regulates amino acid metabolism and resistance to oxidative stress. Mol Cell 2003; 11: 619-633.

8. Marciniak SJ, Yun CY, Oyadomari S, Novoa I, Zhang Y, Jungreis R et al. CHOP induces death by promoting protein synthesis and oxidation in the stressed endoplasmic reticulum. Genes Dev 2004; 18: 3066-3077.

9. Mollereau B, Rzechorzek NM, Roussel BD, Sedru M, Van den Brink DM, Bailly-Maitre B et al. Adaptive preconditioning in neurological diseases - therapeutic insights from proteostatic perturbations. Brain Res 2016; 1648: 603-616.

10. Rissanen A, Sivenius J, Jolkkonen J. Prolonged bihemispheric alterations in unfolded protein response related gene expression after experimental stroke. Brain Res 2006; 1087: 60-66.

11. Nakka VP, Gusain A, Raghubir R. Endoplasmic reticulum stress plays critical role in brain damage after cerebral ischemia/reperfusion in rats. Neurotox Res 2010; 17: 189-202.

12. Szydlowska K, Tymianski M. Calcium, ischemia and excitotoxicity. Cell Calcium 2010; 47: 122-129.

13. Qi X, Okuma Y, Hosoi T, Nomura Y. Edaravone protects against hypoxia/ischemia-induced endoplasmic reticulum dysfunction. J Pharmacol Exp Ther 2004; 311: 388-393.

14. Tajiri S, Oyadomari S, Yano S, Morioka M, Gotoh T, Hamada Jl et al. Ischemia-induced neuronal cell death is mediated by the endoplasmic reticulum stress pathway involving CHOP. Cell Death Differ 2004; 11: 403-415.

15. Hayashi T, Saito A, Okuno S, Ferrand-Drake M, Dodd RL, Chan PH. Damage to the endoplasmic reticulum and activation of apoptotic machinery by oxidative stress in ischemic neurons. J Cereb Blood Flow Metab 2005; 25: 41-53.

16. Paschen $\mathrm{W}$, Hayashi T, Saito A, Chan PH. GADD34 protein levels increase after transient ischemia in the cortex but not in the CA1 subfield: implications for post-ischemic recovery of protein synthesis in ischemia-resistant cells. J Neurochem 2004; 90: 694-701.

17. McCaig D, Imai H, Gallagher L, Graham DI, Harland J, Moira Brown S et al. Evolution of GADD34 expression after focal cerebral ischaemia. Brain Res 2005; 1034: 51-61. 
18. Chaveroux C, Carraro V, Canaple L, Averous J, Maurin AC, Jousse $C$ et al. In vivo imaging of the spatiotemporal activity of the elF2alpha-ATF4 signaling pathway: Insights into stress and related disorders. Sci Signal 2015; 8: rs5.

19. Orset C, Macrez R, Young AR, Panthou D, Angles-Cano E, Maubert E et al. Mouse model of in situ thromboembolic stroke and reperfusion. Stroke 2007; 38: 2771-2778.

20. Chevilley A, Lesept F, Lenoir S, Ali C, Parcq J, Vivien D. Impacts of tissue-type plasminogen activator (tPA) on neuronal survival. Front Cell Neurosci 2015; 9: 415

21. Yepes M. Tissue-type plasminogen activator is a neuroprotectant in the central nervous system. Front Cell Neurosci 2015; 9: 304.

22. Yepes M, Roussel BD, Ali C, Vivien D. Tissue-type plasminogen activator in the ischemic brain: more than a thrombolytic. Trends Neurosci 2009; 32: 48-55.

23. Correa F, Gauberti M, Parcq J, Macrez R, Hommet Y, Obiang P et al. Tissue plasminogen activator prevents white matter damage following stroke. J Exp Med 2011; 208: 1229-1242.

24. Lemarchand E, Maubert E, Haelewyn B, Ali C, Rubio M, Vivien D. Stressed neurons protect themselves by a tissue-type plasminogen activator-mediated EGFR-dependent mechanism. Cell Death Differ 2015

25. Zhang X, Polavarapu R, She H, Mao Z, Yepes M. Tissue-type plasminogen activator and the low-density lipoprotein receptor-related protein mediate cerebral ischemia-induced nuclear factor-kappaB pathway activation. Am J Pathol 2007; 171: 1281-1290.

26. An J, Zhang C, Polavarapu R, Zhang X, Yepes M. Tissue-type plasminogen activator and the low-density lipoprotein receptor-related protein induce Akt phosphorylation in the ischemic brain. Blood 2008; 112: 2787-2794.

27. Gonzalez-Gronow M, Selim MA, Papalas J, Pizzo SV. GRP78: a multifunctional receptor on the cell surface. Antioxid Redox Signal 2009; 11: 2299-2306.

28. Tsai YL, Zhang Y, Tseng CC, Stanciauskas R, Pinaud F, Lee AS. Characterization and mechanism of stress-induced translocation of 78-kilodalton glucose-regulated protein (GRP78) to the cell surface. J Biol Chem 2015; 290: 8049-8064.

29. Gonzalez-Gronow M, Gomez CF, de Ridder GG, Ray R, Pizzo SV. Binding of tissue-type plasminogen activator to the glucose-regulated protein 78 (GRP78) modulates plasminogen activation and promotes human neuroblastoma cell proliferation in vitro. J Biol Chem 2014; 289: 25166-25176.

30. Kumar R, Azam S, Sullivan JM, Owen C, Cavener DR, Zhang P et al. Brain ischemia and reperfusion activates the eukaryotic initiation factor 2alpha kinase, PERK. $J$ Neurochem 2001; 77: 1418-1421.

31. Owen CR, Kumar R, Zhang P, McGrath BC, Cavener DR, Krause GS. PERK is responsible for the increased phosphorylation of elF2alpha and the severe inhibition of protein synthesis after transient global brain ischemia. J Neurochem 2005; 94: 1235-1242.

32. Zhang Y, Liu R, Ni M, Gill P, Lee AS. Cell surface relocalization of the endoplasmic reticulum chaperone and unfolded protein response regulator GRP78/BiP. J Biol Chem 2010; 285: 15065-15075.

33. Hardy B, Battler A, Weiss C, Kudasi O, Raiter A. Therapeutic angiogenesis of mouse hind limb ischemia by novel peptide activating GRP78 receptor on endothelial cells. Biochem Pharmacol 2008; 75: 891-899.

34. Raiter A, Weiss C, Bechor Z, Ben-Dor I, Battler A, Kaplan B et al. Activation of GRP78 on endothelial cell membranes by an ADAM15-derived peptide induces angiogenesis. $J$ Vasc Res 2010; 47: 399-411.

35. Misra UK, Gonzalez-Gronow M, Gawdi G, Hart JP, Johnson CE, Pizzo SV. The role of Grp 78 in alpha 2-macroglobulin-induced signal transduction. Evidence from RNA interference that the low density lipoprotein receptor-related protein is associated with, but not necessary for, GRP 78-mediated signal transduction. J Biol Chem 2002; 277: 42082-42087.

36. Gonzalez-Gronow M, Kaczowka SJ, Payne S, Wang F, Gawdi G, Pizzo SV. Plasminogen structural domains exhibit different functions when associated with cell surface GRP78 or the voltage-dependent anion channel. J Biol Chem 2007; 282: 32811-32820.

37. Jindadamrongwech S, Thepparit C, Smith DR. Identification of GRP 78 (BiP) as a liver cell expressed receptor element for dengue virus serotype 2. Arch Virol 2004; 149: 915-927.

38. Triantafilou K, Fradelizi D, Wilson K, Triantafilou M. GRP78, a coreceptor for coxsackievirus A9, interacts with major histocompatibility complex class I molecules which mediate virus internalization. J Virol 2002; 76: 633-643.

39. Goldenberg-Cohen N, Raiter A, Gaydar V, Dratviman-Storobinsky O, Goldstein T, Weizman A et al. Peptide-binding GRP78 protects neurons from hypoxia-induced apoptosis. Apoptosis 2012; 17: 278-288.
40. Tissue plasminogen activator for acute ischemic stroke. The National Institute of Neurological Disorders and Stroke rt-PA Stroke Study Group. N Engl J Med 1995; 333: 1581-1587.

41. Kim JT, Fonarow GC, Smith EE, Reeves MJ, Navalkele DD, Grotta JC et al. Treatment with TPA in the "Golden Hour" and the shape of the 4.5 hour time-benefit curve in the National US Get With The Guidelines-Stroke Population. Circulation 2016; 135: 128-139.

42. Tsirka SE, Gualandris A, Amaral DG, Strickland S. Excitotoxin-induced neuronal degeneration and seizure are mediated by tissue plasminogen activator. Nature 1995; 377 340-344.

43. Nicole O, Docagne F, Ali C, Margaill I, Carmeliet P, MacKenzie ET et al. The proteolytic activity of tissue-plasminogen activator enhances NMDA receptor-mediated signaling. Nat Med 2001; 7: 59-64.

44. Liot G, Roussel BD, Lebeurrier N, Benchenane K, Lopez-Atalaya JP, Vivien D et al. Tissue-type plasminogen activator rescues neurones from serum deprivation-induced apoptosis through a mechanism independent of its proteolytic activity. J Neurochem 2006; 98: 1458-1464.

45. Parcq J, Bertrand T, Montagne A, Baron AF, Macrez R, Billard JM et al. Unveiling an exceptional zymogen: the single-chain form of TPA is a selective activator of NMDA receptor-dependent signaling and neurotoxicity. Cell Death Differ 2012; 19: 1983-1991.

46. Wu F, Nicholson AD, Haile WB, Torre E, An J, Chen C et al. Tissue-type plasminogen activator mediates neuronal detection and adaptation to metabolic stress. J Cereb Blood Flow Metab 2013; 33: 1761-1769.

47. Wu F, Echeverry R, Wu J, An J, Haile WB, Cooper DS et al. Tissue-type plasminogen activator protects neurons from excitotoxin-induced cell death via activation of the ERK1/2-CREB-ATF3 signaling pathway. Mol Cell Neurosci 2013; 52: 9-19.

48. Wang YF, Tsirka SE, Strickland S, Stieg PE, Soriano SG, Lipton SA. Tissue plasminogen activator (tPA) increases neuronal damage after focal cerebral ischemia in wild-type and tPA-deficient mice. Nat Med 1998; 4: 228-231.

49. Lesept F, Chevilley A, Jezequel J, Ladepeche L, Macrez R, Aimable M et al. Tissue-type plasminogen activator controls neuronal death by raising surface dynamics of extrasynaptic NMDA receptors. Cell Death Dis 2016; 7: e2466.

50. Hardy B, Raiter A. Peptide-binding heat shock protein GRP78 protects cardiomyocytes from hypoxia-induced apoptosis. J Mol Med (Berl) 2010; 88: 1157-1167.

51. Raiter A, Tenenbaum A, Yackobovitch-Gavan M, Battler A, Hardy B. Peptide binding glucose regulated protein 78 improves type 1 diabetes by preventing pancreatic beta cell apoptosis. Exp Clin Endocrinol Diabetes 2016; 124: 239-245.

52. Kudo T, Kanemoto S, Hara H, Morimoto N, Morihara T, Kimura R et al. A molecular chaperone inducer protects neurons from ER stress. Cell Death Differ 2008; 15: 364-375.

53. Oida Y, Hamanaka J, Hyakkoku K, Shimazawa M, Kudo T, Imaizumi K et al. Post-treatment of a BiP inducer prevents cell death after middle cerebral artery occlusion in mice. Neurosci Lett 2010; 484: 43-46.

54. B'Chir W, Maurin AC, Carraro V, Averous J, Jousse C, Muranishi Y et al. The elF2alpha/ ATF4 pathway is essential for stress-induced autophagy gene expression. Nucleic Acids Res 2013; 41: 7683-7699.

55. Baron A, Montagne A, Casse F, Launay S, Maubert E, Ali C et al. NR2D-containing NMDA receptors mediate tissue plasminogen activator-promoted neuronal excitotoxicity. Cell Death Differ 2010; 17: 860-871.

56. Rozen S, Skaletsky H. Primer3 on the WWW for general users and for biologis programmers. Methods Mol Biol 2000; 132: 365-386.

57. Bruckert G, Vivien D, Docagne F, Roussel BD. Normalization of reverse transcription quantitative PCR data during ageing in distinct cerebral structures. Mol Neurobiol 2015; 53 : $1540-1550$.

58. Leprince J, Gandolfo P, Thoumas JL, Patte C, Fauchere JL, Vaudry H et al. Structure-activity relationships of a series of analogues of the octadecaneuropeptide ODN on calcium mobilization in rat astrocytes. J Med Chem 1998; 41: 4433-4438.

59. Leprince J, Oulyadi H, Vaudry D, Masmoudi O, Gandolfo P, Patte C et al. Synthesis, conformational analysis and biological activity of cyclic analogs of the octadecaneuropeptide ODN. Design of a potent endozepine antagonist. Eur J Biochem 2001; 268: 6045-6057.

60. Chatenet D, Dubessy C, Boularan C, Scalbert E, Pfeiffer B, Renard P et al. Structure-activity relationships of a novel series of urotensin II analogues: identification of a urotensin II antagonist. J Med Chem 2006; 49: 7234-7238.

Supplementary Information accompanies this paper on Cell Death and Differentiation website (http://www.nature.com/cdd) 